\title{
Predictive ground motion scaling in Switzerland: Best estimates and uncertainties
}

\section{Journal Article}

\section{Author(s):}

Bay, Francesca; Wiemer, Stefan (Di); Fäh, Donat; Giardini, Domenico

Publication date:

2005-04

\section{Permanent link:}

https://doi.org/10.3929/ethz-b-000413065

Rights / license:

In Copyright - Non-Commercial Use Permitted

Originally published in:

Journal of Seismology 9(2), https://doi.org/10.1007/s10950-005-5129-0 


\title{
Predictive ground motion scaling in Switzerland: Best estimates and uncertainties
}

\author{
Francesca Bay ${ }^{1,2}$, Stefan Wiemer ${ }^{1, *}$, Donat Fäh ${ }^{1} \&$ Domenico Giardini ${ }^{1}$ \\ ${ }^{1}$ Swiss Seismological Service, ETH Zurich, Hoenngerberg HPP P5, 8093 Zurich, Switzerland; ${ }^{2}$ Now at: \\ Interkantonaler Rückversicherungsverband, Bern; \\ *Author for correspondence: e-mail: stefan.wiemer@sed.ethz.ch
}

Received 24 May 2004; accepted in revised form 6 April 2005

Key words: attenuation, ground motions, seismic hazard, stress drop, Switzerland

\begin{abstract}
Spectral ground motion ( 1 to $15 \mathrm{~Hz}$ ) as a function of distance is modeled for events spanning $3.0<M_{\mathrm{w}} \leq 7.0$ in Switzerland. The parameters required to simulate ground motion with a stochastic approach are inverted from 2958 horizontal and vertical component waveforms of small to moderate size events $\left(2.0 \leq M_{\mathrm{L}} \leq 5.2\right)$ in the distance range 10 to $300 \mathrm{~km}$ recorded on hard rock sites. Using a Monte Carlo simulation, we establish a significantly different amplification of about a factor of 1.9 between the Alpine Foreland and the Alps. To assess the trade-off between the free parameters of our stochastic model and their influence on the predictive ground motion relationship, we perform a grid search over the five-dimensional solution space. The uncertainties are separated into epistemic and aleatory parts; the main epistemic uncertainty is attributed to the lack of data for $M>5$. To constrain the viable models at large magnitudes, results from worldwide scaling studies are evaluated in light of the Swiss data. The model that explains best the low observed stress drops at small magnitudes ( $\Delta \sigma \cong 3$ bar) yet matches observed intensities of historical earthquakes assumes a stress drop increasing with moment as $M_{0}^{0.25}$. For three sites in Switzerland we evaluate the sensitivity of the epistemic uncertainty by computing probabilistic hazard curves. Our model offers the most comprehensive and detailed study of spectral ground motion for Switzerland to date.
\end{abstract}

\section{Introduction}

Ground-motion relations, which estimate peak ground motions or response spectral ordinates as a function of earthquake magnitude and distance, are critical to assessing seismic hazard and designing earthquakeresistant structures. Ground-motion relations require a calibration for the region of interest, because of commonly observed differences between diverse seismotectonic regimes, crustal structures and site conditions. A number of ground motion relationships have been proposed for central Europe in the last two decades. Most studies adopt a functional form introduced by Joyner and Boore (1981), with a constant geometrical spreading for all distances (e.g., Sabetta and Pugliese, 1987 (Italy); Ambraseys et al., 1996 (Europe); Smit, 1996 (Switzerland)). Smit's (1996) work, which aims to estimate ground motion in Switzerland, is restricted to Fourier spectral and peak ground accelerations. Because horizontal component data were insufficient, Smit (1996) applied a generic factor $(\mathrm{H} / \mathrm{V}=1.5)$ to derive the attenuation of horizontal ground motion from the vertical. A different approach recently applied by Malagnini et al. (2000a,b) in Italy and Germany as well as by Malagnini and Herrmann (2000) in Italy uses a stochastic simulation method (McGuire and Hanks, 1980; Hanks and McGuire, 1981; Boore, 1983; Yazd, 1993; Raoof et al., 1999) to predict ground motions.

Following the stochastic approach, Bay et al. (2003) developed a spectral attenuation model for Switzerland and derived empirical excitation terms for 292 events within the magnitude range $2.0 \leq M_{\mathrm{L}} \leq 5.2$. Here we investigate how these attenuation functionals and excitation terms can be used to constrain predictive 
ground motion estimates in Switzerland for the magnitude range $3.0 \leq M_{\mathrm{w}} \leq 7.0$ and frequency range 1 to $15 \mathrm{~Hz}$. Our derived ground motion estimates are Fourier spectral velocities, peak filtered velocities and pseudo spectral Accelerations (PSA). The modeling is based on Fourier spectral velocities. To check the reliability of our model parameters, we apply Random Vibration Theory (Cartwright and Longuet-Higgins, 1956) to predict time-domain models and compare them to the peak-filtered data. Since we develop a stochastic model, results can readily be used to compute any strong motion parameter required (Boore, 1983).

Developing ground motion relationships in areas of moderate seismicity such as Switzerland is complicated by scarce data for larger events. In such areas, it is therefore particularly important to quantitatively assess uncertainties in ground motion scaling. Uncertainties in ground motion and resulting uncertainties in seismic hazard tend to be larger in areas of low to moderate seismicity than in regions of higher activity. Uncertainties are commonly separated into aleatory and epistemic components (e.g., Toro et al., 1997). Aleatory uncertainty (randomness) reflects the intrinsic variability of ground motion and cannot be reduced with more or better observations. By contrast, epistemic uncertainty results from inaccurate or incomplete information and can be reduced or eliminated given better models or additional observations. In our study epistemic uncertainty is caused mainly by the lack of large events in the observational data set. To quantify the trade-off between the free parameters of our stochastic model and the resulting uncertainty in the predictive ground motion, we apply a new approach that employs a grid search over the entire solution space.

Earthquake scaling is a currently much debated topic (McGarr, 1999; Mayeda and Walter, 1996; Ide and Beroza, 2001, Ide et al., 2003, Perez-Campos et al., 2003). Even in areas with excellent monitoring and data sets containing several large events, such as California or Japan, it is unknown if stress drop is constant or scales with magnitude. We compare results from scaling studies of areas of high seismic activity (Mayeda and Walter, 1996; Ide and Beroza, 2001) to constrain the range of possible ground motion models for Switzerland.

Because of Switzerland's tectonic setting (the contrast between the Alps and the Molasse), significant regional differences in site amplifications are observed. To facilitate hazard assessment until detailed regional models based on shear-wave velocity profiles may become available, we rely on using regional amplification factors derived from weak motion seismograms. We believe that it is important to show that such regionalization gives statistically significant predictions. Therefore, using the Monte Carlo simulation method, we propose a novel test to determine the statistical significance of our site parameterization.

\section{Tectonics of the study area}

Switzerland contains several distinct geological and seismotectonic regimes related to the collision between the African and the European plates. The country can be subdivided into three main tectonic units: (1) the Alpine belt in the south, (2) the Jura in the north and (3) the Molasse basin, lying between (e.g., Trümpy, 1985; Hsü, 1995; Pavoni et al., 1997) (Figure 1). Small to moderate but persistent seismic activity occurs beneath the Alpine belt and north of the Alps, including the Molasse basin, the Rhine Graben fault and the Jura (Deichmann et al., 2000). Catastrophic earthquakes have occurred in the past, but their return period exceeds 1000 years (Fäh et al., 2003; Meghraoui et al., 2001). Nevertheless, high seismic risk results from the high degree of industrialization and the lack of earthquake preparedness due to the long return periods. The largest earthquake north of the Alps occurred in 1356 in the Basel area and had an epicentral intensity IX (Fäh et al., 2003). Earthquakes are found to be deeper in the Alpine foreland $($ mean depth $=13 \mathrm{~km}$ ) than in the Alps (mean depth $=7 \mathrm{~km})$ (Deichmann, 1992). Stress-tensor inversion results (Kastrup et al., 2003) indicate a different stress regime in the SW-Alps, where normal faulting mechanisms dominate, as compared to northern and central Switzerland, where strike-slip to normalfaulting mechanism dominate. Thrust events are rare.

\section{The stochastic model of ground motion}

\section{Method}

We derive a predictive ground motion relationship from an empirically based stochastic point-source ground motion model (Boore, 1983). Our approach is based on Malagnini et al. (2000a,b) and Malagnini and Herrmann (2000) and a number of ground motion studies for Eastern North American (e.g., Toro and McGuire, 1987; EPRI, 1988; Atkinson and Boore, 1995). The stochastic model uses simplified yet physically based representations of seismic energy release and wave propagation to obtain predictions of ground motion amplitude, $A\left(M_{0}, r, f\right)$ for a given seismic moment $M_{0}$, 

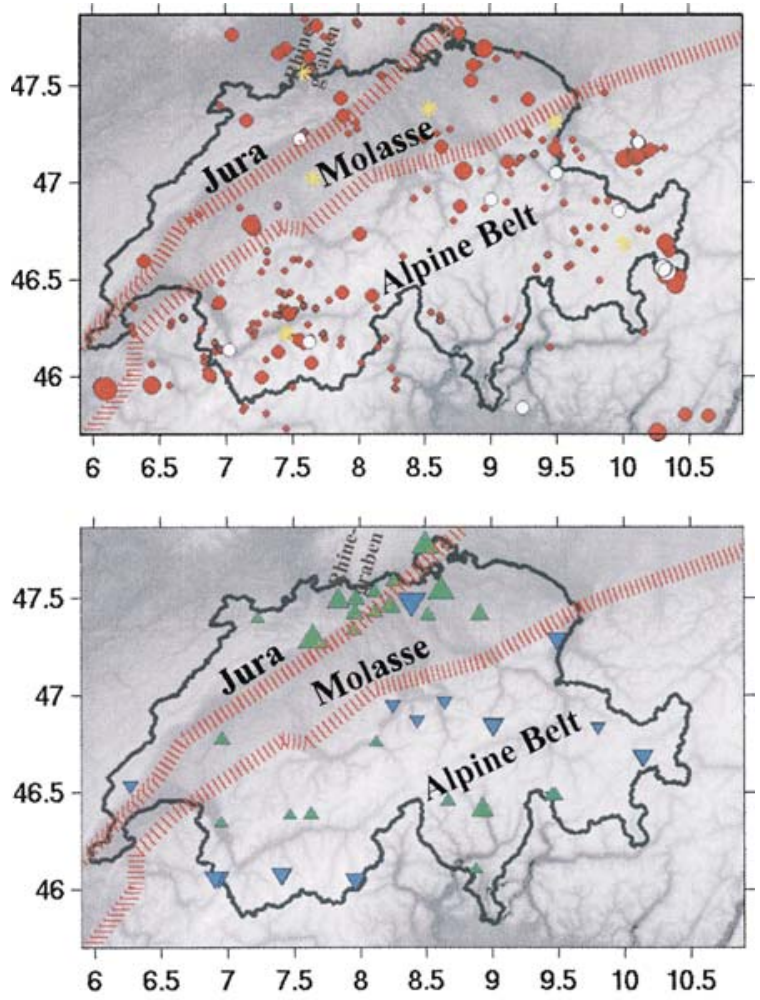

$$
\begin{aligned}
& \text { (2) } \mathrm{M}<3,3 \text { to } 4,4 \text { to } 5,>5 \\
& \text { Events between Jan. } 1984 \text { and Jan. } 2000 \text { ( } \mathrm{M}=\mathrm{ML}) \\
& \text { Events after Nov. } 1999 \text { ( } \mathrm{M}=\mathrm{Mw}) \\
& \text { Sites for which hazard is computed } \\
& \text { Station with pos. residual, size proportional residual } \\
& \text { V Station with neg. residual }
\end{aligned}
$$

Figure 1. Top frame: Map of Switzerland. Red dots mark epicenters of events included in the development of an attenuation functional (Bay et al., 2003), a total of 292 events between Jan. 1984 to Jan. 2000. White dots mark epicenters of events recorded after Nov. 1999, which are used to independently check the source scaling in this study (Figure 7). Stars mark six sites for which hazard is computed (Figures 13 to 16). Bottom frame: Map of Switzerland. Triangles mark recording stations; average site residuals are indicated for each station (blue: negative residual, green: positive). The size of the triangle is proportional to the residual.

hypocentral distances $r$ and frequency $f$ :

$$
A\left(M_{0}, r, f\right)=E\left(M_{0}, f\right) D(f, r) V(f) I(f)
$$

$E\left(M_{0}, f\right)$ is the excitation spectrum at the reference distance $\left(r_{\text {ref }}=40 \mathrm{~km}\right), D(f, r)$ is the attenuation of ground motion, $V(f)$ is a generic rock-site amplification term, $I(f)$ is a filter for shaping the spectrum to the ground motion measure of interest. For example, to compute the response spectrum, $I$ is the response of an oscillator to ground motion. by:

The general form of the excitation spectra is given

$$
E\left(M_{0}, f\right)=2 \pi f C M_{0} S\left(M_{0}, f\right) P(f)
$$

$C$ is a constant of proportionality and $S\left(M_{0}, f\right)$ is computed using Brune's $(1970,1971)$ single-corner frequency source model (under the assumption that frictional stress equals final stress):

$$
S\left(M_{0}, f\right)=\frac{1}{1+\left(f / f_{c}\right)^{2}}
$$

The corner frequency $f_{c}$ is written as:

$$
f_{c}=4.9 \times 10^{6} v_{s}\left(\frac{\Delta \sigma}{M_{0}}\right)^{1 / 3}
$$

where $\Delta \sigma$ refers to the static stress drop. However, the dynamic stress drop may be more relevant to the excitation of high frequency ground motion (Atkinson, 1984; Boatwright, 1984), as Brune originally proposed. Boore (1983) suggests that this parameter should be considered simply a measure of the strength of high frequency ground motion, not as stress drop per se. The average shear wave velocity near the source $v_{\mathrm{s}}$ is $=3.5 \mathrm{~km} / \mathrm{s}$.

Magnitudes determined by the Swiss Seismological Service (SED) are mainly $M_{\mathrm{L}}$. Since 199930 new STS2 broadband stations have been installed in Switzerland, so estimates of $M_{\mathrm{w}}$ now exist for larger events. By comparing 30 earthquakes for which both $M_{\mathrm{L}}$ and $M_{\mathrm{w}}$ are available, Braunmiller et al. (2005) derived the relationship: $M_{\mathrm{w}}=M_{\mathrm{L}}-0.2$; which we apply to compute $M_{\mathrm{w}}$ and $M_{0}$, respectively. We later verify that this regression fits our excitation spectra well.

To propagate the source spectrum to the reference distance, the propagation-term is applied:

$$
P(f)=G\left(r_{\mathrm{ref}}\right) e^{-\pi f r_{\mathrm{ref}} / Q(f) v_{s}} e^{-\pi \kappa_{0} f}
$$

where $Q(f)=Q_{0} f^{\eta}$ is the crustal anelastic attenuation, and $G\left(r_{\text {ref }}\right)$ is the geometrical spreading. The term $e^{-\pi k_{0} f}$ represents the increased anelastic attenuation at shallow depths (Anderson and Hough, 1984), the constant $\kappa_{0}$ describes a regional average of the shallow attenuation.

The attenuation of ground motion is parameterized by:

$$
D(f, r)=G(r) / G\left(r_{\text {ref }}\right) e^{-\pi f\left(r-r_{\text {ref }}\right) / Q(f) v_{s}}
$$


$G(r)$ is modeled as a piecewise linear function between four selected node distances. $D(f, r)$ is assumed to be one at a reference distance $r_{\text {ref }}$, which defines the excitation term.

The final input element of the stochastic predictions is the duration of motion: $T=T_{0}+T(f, r)$, where $T_{0}$ is the source duration and $T(f, r)$ represents a distance dependent term which accounts for scattering and dispersion. Following Boatwright and Choy (1992), we assume that $T_{0}=1 / 2 f_{\mathrm{c}}$, where $f_{c}$ is the corner frequency in the source spectrum.

To develop a stochastic model of ground motion and assess its uncertainty, we use as input empirical excitation and site terms and the distance dependent duration and attenuation model developed by Bay et al. (2003), who adopted the approach outlined by Yazd (1993), Raoof et al. (1999) and Malagnini et al. (2000a,b). Results are summarized in Figure 2. Model parameters of the attenuation and duration are listed along with the results of this study in Table 1 and marked with a star $\left(^{*}\right)$.

Bay et al. (2003) analyzed 2958 three-component short period and broadband waveforms, recorded by the network of the Swiss Seismological Service at distances of 5 to $300 \mathrm{~km}$. All stations are located on NEHRP (1994) site class A or B. Magnitudes range from $2.0 \leq M_{\mathrm{L}} \leq 5.2$; about 80 percent of the data come from the magnitude range $2.0 \leq$ $M_{\mathrm{L}} \leq 3.0$ (Figure 1). The ground motion parameter, $A_{i j}\left(f_{k}\right)$, which is either the peak filtered- or the Fourier spectral-velocity at the central frequency $f_{k}$, was
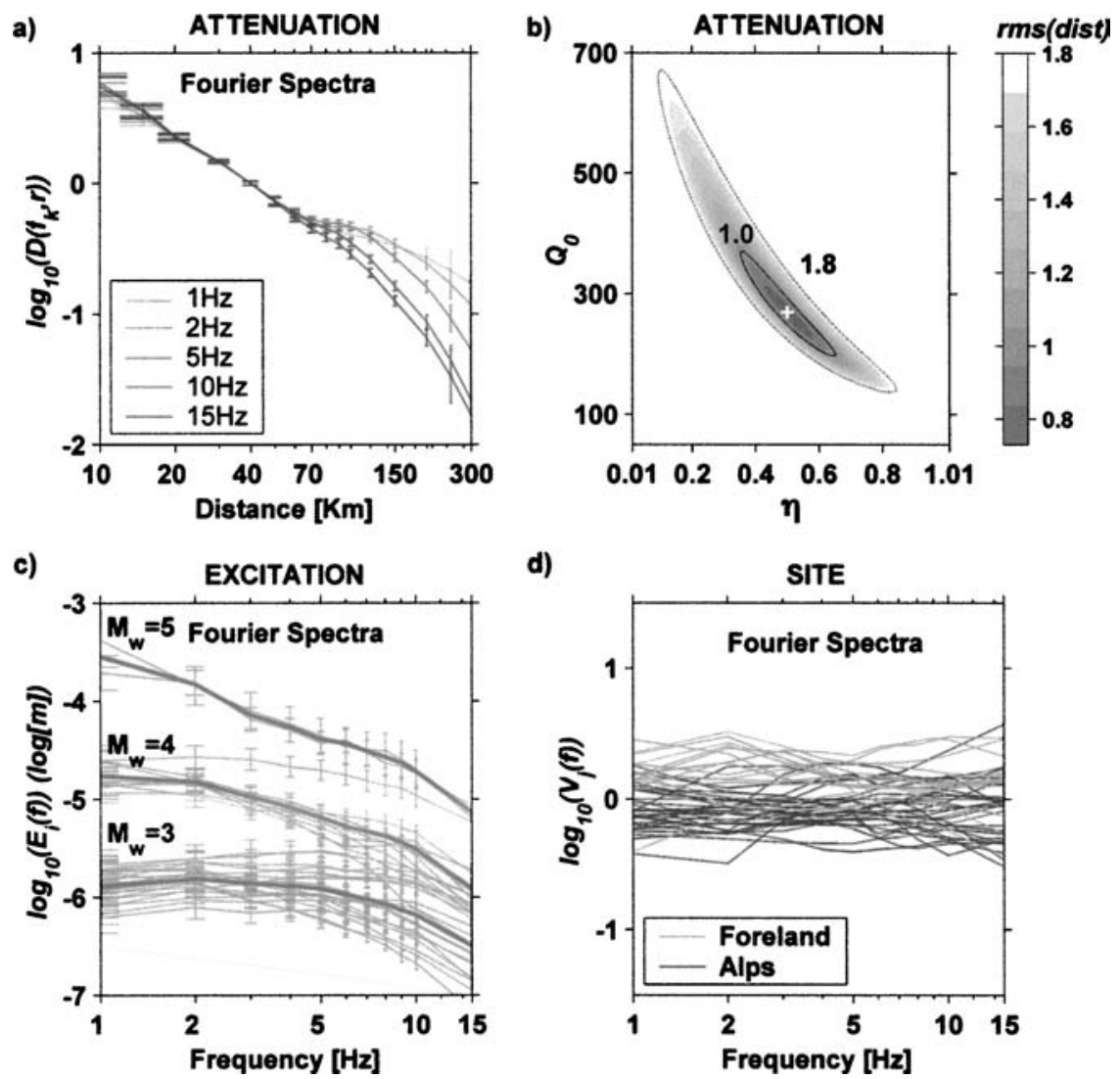

Figure 2. Summary of the input data used to development of the predictive ground motion scaling. Attenuation-, excitation-, and site terms were derived by Bay et al. (2003) based on a least squares regression analysis of the Fourier spectra of 2985 vertical and horizontal component seismograms. a) Attenuation term $\left(\log _{10}\left(D\left(f_{k}, r\right)\right)\right)$, normalized to zero at $40 \mathrm{~km}$. Shown are the vertical components at $1 \mathrm{~Hz}, 2 \mathrm{~Hz}, 5 \mathrm{~Hz}, 10 \mathrm{~Hz}$ and $15 \mathrm{~Hz}$. b) Residuals (rms(dist)) obtained from comparing empirical $\log _{10}\left(D\left(f_{k}, r\right)\right)$ and theoretical $\log _{10}(D(f, r))$ of the vertical components, plotted as a function of $Q_{0}$ and $\eta$. Small residuals indicate a good fit between the theoretical and empirical attenuation. The minimum value, $r m s($ dist $)=0.73$ (white cross), is marked, and black solid and black dashed lines contour $r m s$ (dist) $=1$ and 1.8 , respectively. c) Excitation term, $\left(E_{i}(f)\right)$ of the vertical components at $40 \mathrm{~km}$ hypocentral distance in the frequency range 1 to $15 \mathrm{~Hz}$ for events i ranging between $M_{\mathrm{w}}=2.8$ to $3.2,3.8$ to 4.2 and 4.8 to 5.2 (thin gray lines). Thick gray lines mark the average values. d) Site term $\left(\log _{10} V_{j}(f)\right)$ of the vertical components in the frequency range of $1 \mathrm{~Hz}$ to $15 \mathrm{~Hz}$ for station sites i. Gray lines indicate sites in the Alpine Foreland, black lines sites from the Alps. 
Table 1. Summary of ground motion scaling parameters for Switzerland obtained here

\begin{tabular}{|c|c|c|c|}
\hline Parameter & Values & & \\
\hline & & DIST. (KM) & \\
\hline \multirow[t]{4}{*}{$G(r)^{\mathrm{a}}$} & $r^{-1.1}$ & $0-50$ & \\
\hline & $r^{-0.6}$ & $50-70$ & \\
\hline & $r^{+0.2}$ & $70-100$ & \\
\hline & $r^{-0.5}$ & $>100$ & \\
\hline$Q(f)^{\mathrm{a}}$ & & $270 f^{0.50}$ & \\
\hline$\kappa_{0}$ & & 0.0125 & \\
\hline$\Delta \sigma($ bar $)$ & & $M_{\mathrm{w}}$ & \\
\hline \multirow[t]{5}{*}{$A_{\text {inc }}$} & 3 & 3.0 & \\
\hline & 6 & 4.0 & \\
\hline & 15 & 5.0 & \\
\hline & 36 & 6.0 & \\
\hline & 55 & 6.5 & \\
\hline$A_{30}$ & 30 & $>4$ & \\
\hline \multirow[t]{2}{*}{$\sigma_{l g}$} & 0.35 & & \\
\hline & FACTOR () & FREQ. (HZ) & \\
\hline \multirow[t]{11}{*}{$V(f)_{\mathrm{alps}} / V(f)_{\mathrm{averg}}$} & 0.80 & 1.0 & \\
\hline & 0.75 & 2.0 & \\
\hline & 0.80 & 3.0 & \\
\hline & 0.83 & 4.0 & \\
\hline & 0.85 & 5.0 & \\
\hline & 0.84 & 6.0 & \\
\hline & 0.83 & 7.0 & \\
\hline & 0.84 & 8.0 & \\
\hline & 0.83 & 9.0 & \\
\hline & 0.84 & 10.0 & \\
\hline & 0.85 & 15.0 & \\
\hline \multirow[t]{11}{*}{$V(f)_{\text {forl }} / V(f)_{\text {averg }}$} & 1.39 & 1.0 & \\
\hline & 1.59 & 2.0 & \\
\hline & 1.44 & 3.0 & \\
\hline & 1.34 & 4.0 & \\
\hline & 1.29 & 5.0 & \\
\hline & 1.33 & 6.0 & \\
\hline & 1.34 & 7.0 & \\
\hline & 1.34 & 8.0 & \\
\hline & 1.34 & 9.0 & \\
\hline & 1.33 & 10.0 & \\
\hline & 1.29 & 15.0 & \\
\hline \multirow[t]{6}{*}{$\mathrm{H} / \mathrm{V}$} & & FREQ. (HZ) & \\
\hline & 1.3 & 1.0 & \\
\hline & 1.3 & 4.0 & \\
\hline & 1.3 & 8.0 & \\
\hline & 1.2 & 15.0 & \\
\hline & $1 \mathrm{~Hz}$ & $10 \mathrm{~Hz}$ & DIST. (KM) \\
\hline \multirow[t]{6}{*}{$T\left(f_{k}, r\right)(\mathrm{sec})^{\mathrm{a}}$} & 2.4 & 1.8 & 10 \\
\hline & 7.5 & 4.1 & 30 \\
\hline & 14.3 & 7.2 & 75 \\
\hline & 15.0 & 6.9 & 90 \\
\hline & 12.0 & 6.4 & 120 \\
\hline & 11.9 & 6.8 & 150 \\
\hline
\end{tabular}

${ }^{\mathrm{a}}$ From Bay et al. (2003) parameterized applying an iterative damped least square regression:

$$
A_{i j}\left(f_{k}\right)=E_{i}\left(f_{k}\right) D\left(f_{k}, r\right) V_{j}\left(f_{k}\right)
$$

$E_{i}\left(f_{k}\right)$ is the excitation, $D\left(f_{k}, r\right)$ the attenuation and $V_{j}\left(f_{k}\right)$ the site term for event $i$ observed at site $j$. An independent inversion was performed for each central frequency $f_{k}$. Figure $2 \mathrm{a}-\mathrm{d}$ shows the results. In the next step we performed a grid search through the parameter space of $G(r), Q_{0}$ and $\eta$ to find the attenuation model (Eq. (6)) which best fits the empirical attenuation term. In addition, we defined an uncertainty of the model parameters by finding all models which agree with the empirical attenuation term within the error $(r m s(D)=1)$. Figure $2 \mathrm{~b}$ plots a slice of the solution space with the optimum $G(r)$ fixed. The optimum result (white cross; Figure 2b) has an $\operatorname{rms}(D)=0.73$.

\section{Modeling of the excitation spectra}

Our first objective is to find one theoretical excitation model (Eqs. (2)-(5)) for the largest events $\left(M_{\mathrm{w}} \geq 3\right)$ with the parameter combination resulting in the smallest misfit between empirical and theoretical models. Secondly, we assess the sensitivity by analyzing the trade-off between the five model parameters: $\Delta \sigma, \kappa_{0}$, $G\left(r_{\text {ref }}\right), Q_{0}$ and $\eta$. Given the non-linear trade-off between these parameters, it is not sufficient to consider a plus/minus range for each parameter. Instead, we consider pairs that fall within the uncertainty of the empirical model. The parameter space of $G\left(r_{\text {ref }}\right), Q_{0}$ and $\eta$ is defined by parameter configurations which describe the attenuation within its error $(r m s(D) \leq 1)$ (Bay et al., 2003). We allow $\kappa_{0}$ to vary between 0.00 and 0.05 and $\Delta \sigma$ between 0.1 and 100 . Comparable to the attenuation modeling in Bay et al. (2003), we perform a grid search through the entire parameter space of the Fourier domain.

The residual between all empirical- excitation terms and the theoretical model is defined as:

$r m s(E)=\sqrt{\frac{\sum_{k, i}\left(\log _{10} E_{i}\left(f_{k}\right)-\log _{10} E\left(M_{0}, f_{k}\right)\right)^{2}}{\sum_{k, i} \sigma_{i}\left(f_{k}\right)^{2}}}$

whereby $\sigma_{i}\left(f_{k}\right)$ are those resulting from the regression analyses; $f_{k}=1,2,3, \ldots, 10,15 \mathrm{~Hz} ; i=1$, $2, \ldots, 29$ are all events in our data set ranging between $3 \leq M_{\mathrm{w}} \leq 5.2$. We limit our search to the largest 
events, because smaller events are not sensitive to the stress drop computed here. An $\operatorname{rms}(E)<1$ denotes that on average the residual between the observed and predicted excitation terms is smaller than $\sigma_{i}\left(f_{k}\right)$.

The analysis is performed in three steps which are outlined below:

First, we find the solution with the minimum $r m s(E)$. This solution $(r m s(E)=2.13)$ is found for the values: $\Delta \sigma=2.7$ bar, $\kappa_{0}=0.0125, Q(f)=270$, $\eta=0.5, G\left(r_{\text {ref })}=40^{-1.1}\right.$. The resulting model is named $A_{0}$. The fact that the minimal $\operatorname{rms}(E)$ is significantly larger than 1.0 implies that no single parameter configuration can explain on average all excitation terms within one $\sigma_{i}\left(f_{k}\right)$. We believe that this large $\operatorname{rms}(E)$ value is caused by the observed scatter of the excitation terms, which is common to studies of ground motion.

Second we ask how sensitive the residual is to variations in the parameters of the model space. As this is a relatively complex task when analyzing a 5-dimensions parameter space, we slice the space along numerous axes to make sure that we understand the following points:

- The trade-off between $\Delta \sigma, Q_{0}$ and for the fixed optimum $G\left(r_{\text {ref }}\right)=40^{-1.1}$. Figure 3 shows the variation of $r m s(E)$ as a function of $\Delta \sigma, Q_{0}$ ( $x$ and $y$ axis) and $\eta$ (mapped onto the surface with different gray shades). Solutions for two different $\kappa_{0}$ (0.005 and $0.025)$ are shown. From Figure 3 we can observe a

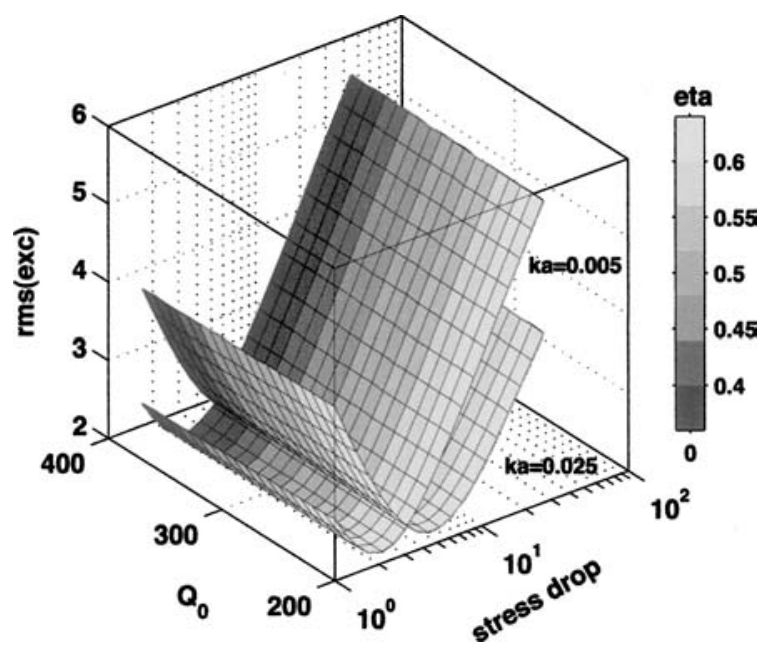

Figure 3. Residual, rms (exc) (z-axis) obtained from comparing empirical and theoretical excitation terms plotted for two different $\kappa_{0}$ $(0.005$ and 0.025$)$ as a function of $\Delta \sigma$ ( $x$-axis), $Q_{0}(y$-axis) and $\eta$. The variation in $\eta$ is shown by the gray shades mapped onto the surfaces of constant $\kappa_{0}$. strong dependence between $\kappa_{0}$ and $\Delta \sigma . Q_{0}$ and $\eta$ trade-off such that they do not greatly influence the residual. They do not significantly trade-off with $\kappa_{0}$ and $\Delta \sigma$.

- The trade-off between $G\left(r_{\text {ref }}\right), \kappa_{0}$ and $\Delta \sigma$. Because we know from the aforementioned analysis that $Q_{0}$ and $\eta$ do not significantly influence $\kappa_{0}$ and $\Delta \sigma$, they are chosen such that the misfit between empiricaland theoretical attenuation is minimized. This is done for each of the three possible $G\left(r_{\text {ref }}\right)$ :

$G\left(r_{\text {ref }}\right)=40^{-1.0} ;$ leads to $Q_{0}=220 ; \eta=0.56$

$G\left(r_{\text {ref }}\right)=40^{-1.1}$; leads to $Q_{0}=270 ; \eta=0.50$

$G\left(r_{\text {ref }}\right)=40^{-1.2}$; leads to $Q_{0}=440 ; \eta=0.37$

The residual is contoured as a function of $\kappa_{0}$ and $\Delta \sigma$ in Figure 4. The minima in each respective frame, marked by black crosses, are termed models $A_{0}, X_{0}$, and $Y_{0}$, respectively. We also mark the $r m s(E)=2.2,2.4$ and 3.0 contour lines. The difference in residual between models $A_{0}$ and $X_{0}$ is $2 \%$; $\Delta \sigma$ changes from 2.7 to 1.3 , a change of $-52 \%$; and $\kappa_{0}$ changes from 0.0125 to 0.0075 , a change of $-40 \%$. The difference in $r m s(E)$ between models $A_{0}$ and $Y_{0}$ is only $0.6 \%$. Both models have the same $\kappa_{0}=0.0125$. However, $\Delta \sigma$ changes from 2.7 to 4.7 , a change of $70 \%$. These results confirm that even sizable changes in parameters can produce only small changes in the residual. Thus, a wide range of models can fit the data almost equally well.

Finally, we assess for different magnitudes the influence of these sensitivities on ground motion excitation. For $M_{\mathrm{w}}=3.0,5.2$, and 6.5 earthquakes we compute excitation spectra at $40 \mathrm{~km}$ hypocentral distance for models $A_{0}$ (thick red line in Figure 5), $X_{0}$ (thick blue line) and $Y_{0}$ (thick yellow line). Even for large magnitudes, all three models result in quite similar excitation terms, despite their considerable differences in parameters. We take this sensitivity analysis one step further by analyzing all models within the $\operatorname{rms}(E)=2.4$ contour line marked in Figure 4. An $\operatorname{rms}(E)=2.4$ represents an increase in the residual of about $10 \%$. These models are plotted as thin, colored lines in Figure 5. For small magnitudes, models with a small $G\left(r_{\text {ref }}\right)$ and, consequently, smaller $\Delta \sigma$ and $\kappa_{0}$ (blue lines) tend to have higher amplitudes in the frequency range 1 to 5 $\mathrm{Hz}$ than models with larger geometrical spreading. But models with a larger $G\left(r_{\text {ref }}\right)$ and consequently higher $\Delta \sigma$ and $\kappa_{0}$ have larger amplitudes at higher magnitudes (yellow lines). Most importantly, the range of possible solutions increases considerably with magnitude. For 


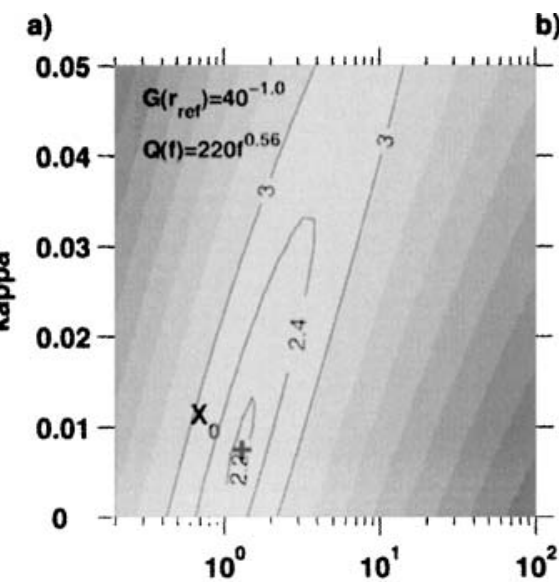

b)

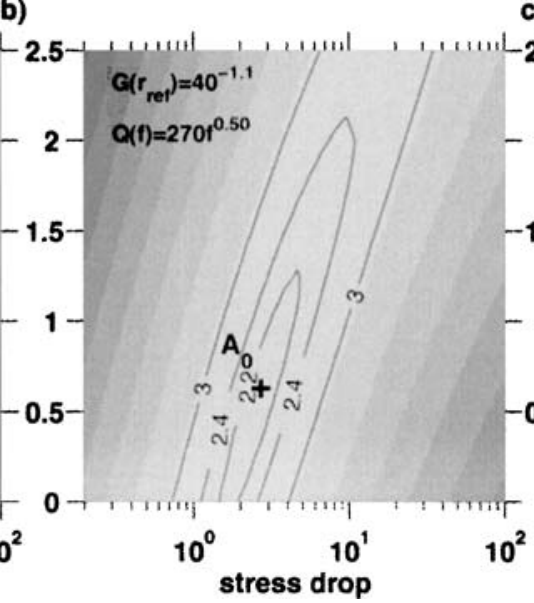

c)

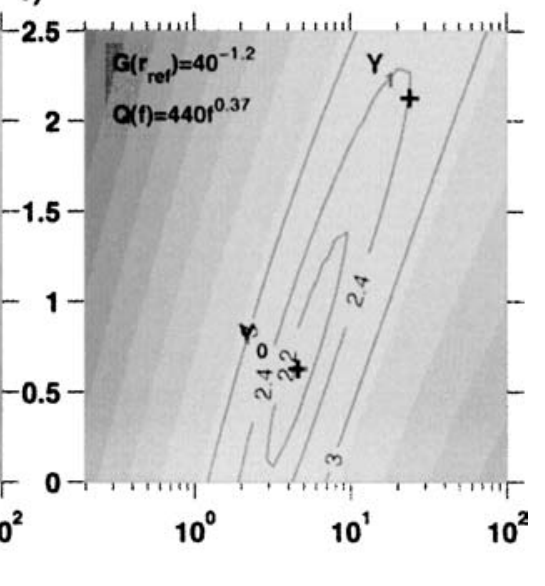

Figure 4. Residual, rms (exc) obtained from comparing empirical and theoretical excitation terms plotted as a function of $\Delta \sigma$ and $\kappa_{0}$ for three $G\left(r_{\text {ref }}\right)$ : a) $G\left(r_{\text {ref }}\right)=40^{-1.0} ; Q(f)=220 f^{0.56}$; b) $G\left(r_{\text {ref }}\right)=40^{-1.1} ; Q(f)=270 f^{0.50}$, c) $G(r)=40^{-1.2}, Q(f)=440 f^{0.37}$. Black crosses mark the respective minima in residual, thin black line contour $\operatorname{rms}($ exc $)=2.2,2.4$ and 3.0.

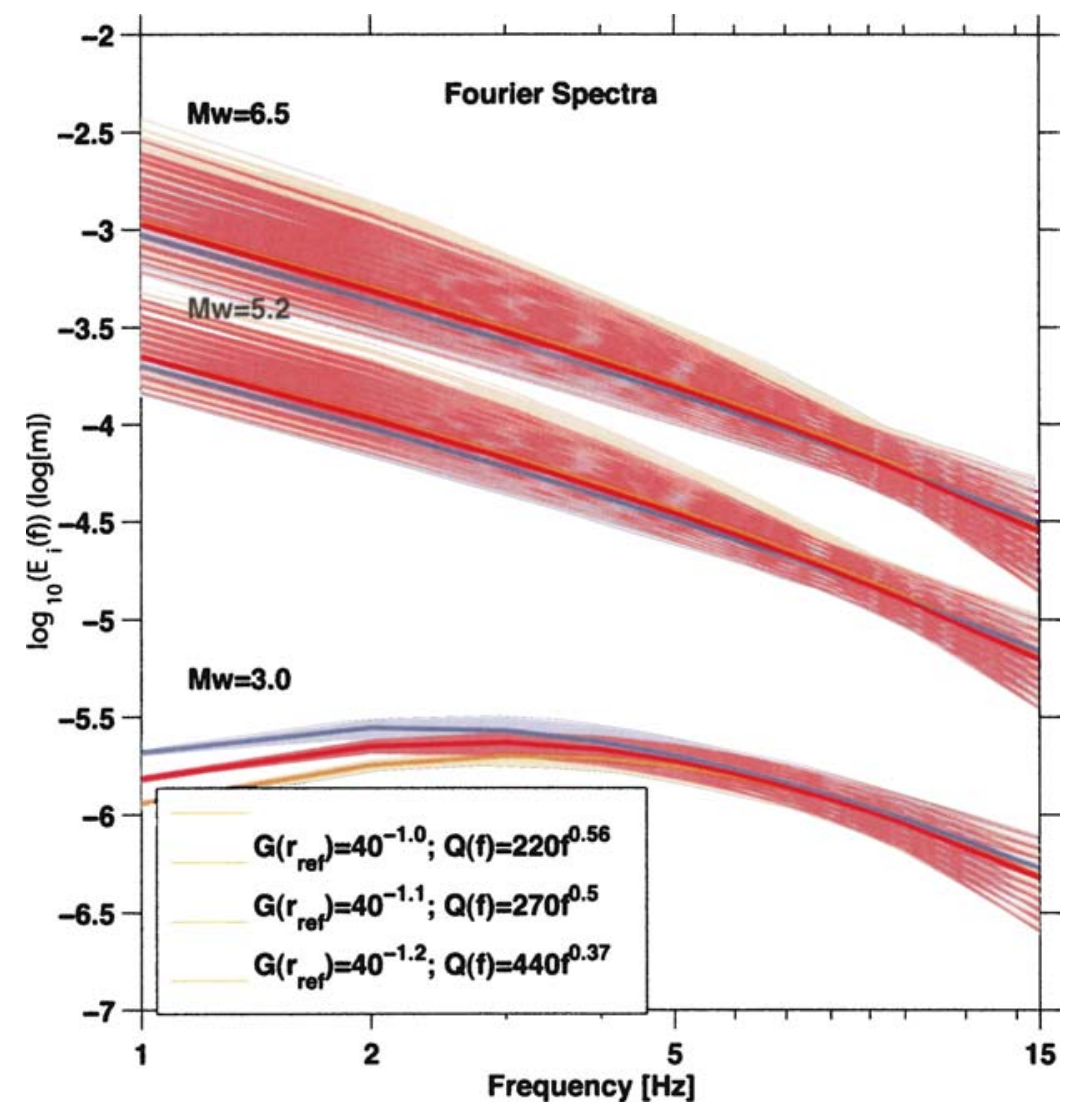

Figure 5. Theoretical excitation terms for $M_{\mathrm{w}}=3.0,5.2$ and 6.5 as a function of frequency. Plotted are all possible excitation models with $r m s(e x c) \leq 2.4$ (Figure 4). Blue lines are computed with $G\left(r_{\text {ref }}\right)=40^{-1}$ and $Q(f)=220 f^{0.56}$; red lines are computed with $G\left(r_{\text {ref }}\right)=40^{-1.1}$ and $Q(f)=270 f^{0.5}$; yellow lines are computed with $G\left(r_{\text {ref }}\right)=40^{-1.2}$ and $Q(f)=440 f^{0.37}$. The thick lines correspond to the respective minima in residual (black crosses in Figure 4). 
$M_{\mathrm{w}}=3.0$, all models are within a narrow range of each other (factor 2 to 3 ), with most scatter observed for the highest frequencies. For $M_{\mathrm{w}}=6.5$, the range of possible solutions reaches a factor of 4 to 6 , with the largest scatter for low frequencies. This difference between the excitation models for larger magnitudes increases even more towards the epicenter. We conclude that, although a range of models can explain the data equally well, they all differ considerably in implications for ground motions of large magnitude events.

\section{Stress drops for individual events}

Stress drop is a critical parameter in ground motion studies, because it directly influences the absolute level of ground motion. It is also a parameter that varies widely in the literature. To appraise stress drops of Swiss earthquakes, we compute individual $\Delta \sigma$ for each event. To compare these stress drops with each other, however, we need to fix all other free parameters. Their choice significantly influences the resulting stress drops. To evaluate how uncertainty in the parameter configuration affects $\Delta \sigma$, we choose two different models: Model $A_{0}$ and a newly defined model $Y_{1}$ (Figure $4 \mathrm{~b}$ ). $A_{0}$ is chosen as the model with the smallest residual. $Y_{1}$ results in the highest $\Delta \sigma$ (24 bars) within the 2.4 contour line, but also has a rather high $\kappa_{0}=0.043$ (Figure 4c).

To compute individual $\Delta \sigma$, Eq. (8) is modified such that the residual, now named $\operatorname{rms}\left(E_{i}\right)$, is computed for each event. Corner frequencies, derived from Eq. (3) and (4) and corresponding to $\Delta \sigma$ for which $r m s\left(E_{i}\right)<1$, are plotted in Figure 6 as a function of $M_{0}$. The figure shows that all $\Delta \sigma$ are below 50 bars. $\Delta \sigma \mathrm{s}$ derived from model $A_{0}$ range mainly between 1 and 10 bars; $\Delta \sigma$ values derived from model $Y_{1}$ range mainly between 5 and 50 bars. We also see in Figure 6 that for a number of empirical excitation spectra, no solution with $\operatorname{rms}\left(E_{i}\right)<1$ can be found for model $Y_{1}$, while for model $A_{0}$ a solution exists. For any given model, the scatter of the individual stress drops is more than a factor of 10 , confirming results from studies that show similar scatter in stress drop (e.g., Kvamme et al., 1995). This also explains why our overall residuum $(\operatorname{rms}(E)=2.13)$ is relatively high. No single model can explain the observed variability in stress drops.

\section{Independent verification of the model}

To independently verify the results, and to provide further constraints for identifying the most suitable model,

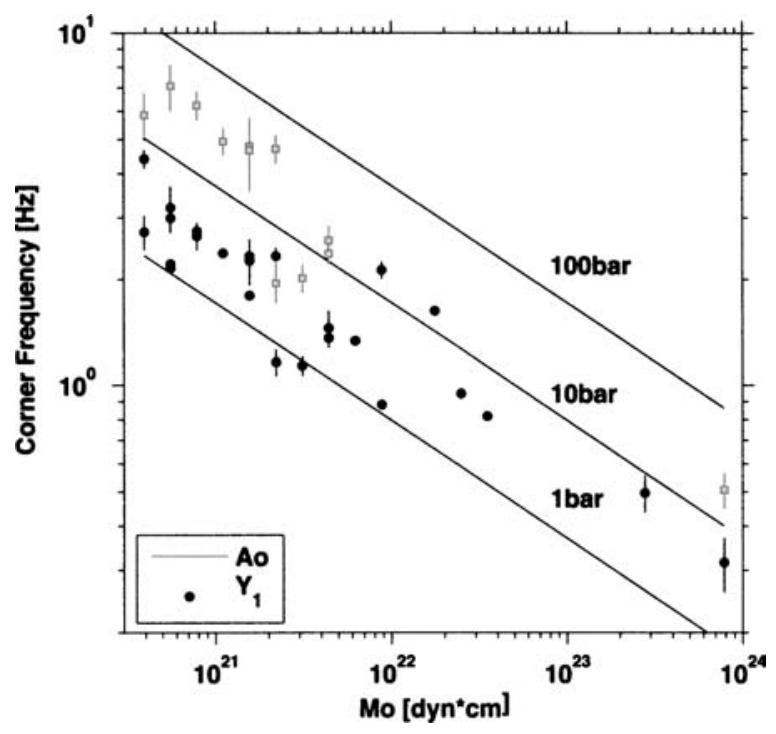

Figure 6. "Corner Frequencies" plotted for two different attenuation models: $A_{0}\left(G\left(r_{\text {ref }}\right)=40^{-1.1}, Q(f)=270 f^{0.5}, \kappa_{0}=0.0125\right.$; dark gray dots) and $Y_{1}\left(G\left(r_{\text {ref }}\right)=40^{-1.2}, Q(f)=440 f^{0.37}, \kappa_{0}=0.043\right.$, light gray squares). Solid lines represent $\Delta \sigma$ of 1,10 and 100 bars. Bars indicate uncertainty in corner frequency estimation.

we analyze broadband recordings of 15 recent events that were not included by Bay et al. (2003). The events are plotted in Figure 1 as white dots and listed in Table 2 . These higher quality data are independently processed from previously used excitation terms. Independent estimates of $M_{\mathrm{w}}$ exist for these earthquakes (Braunmiller et al., 2005), providing us with an important opportunity to check our calibration from $M_{\mathrm{L}}$

Table 2. List of events recorded on broadband stations that were used to verify the results independently

\begin{tabular}{lrrrr}
\hline Event time & & $M_{\mathrm{w}}$ & Depth & Nr. of recordings \\
\hline 1999-12-29 & $20: 42$ & 4.9 & 13 & 12 \\
$1999-12-31$ & $04: 55$ & 4.2 & 15 & 13 \\
$2000-02-22$ & $22: 45$ & 3.1 & 4 & 6 \\
$2000-02-23$ & $04: 06$ & 3.1 & 7 & 13 \\
$2000-04-06$ & $17: 40$ & 4.1 & 15 & 16 \\
$2000-06-03$ & $15: 14$ & 3.6 & 2 & 10 \\
$2000-06-10$ & $05: 50$ & 3.4 & 3 & 9 \\
$2000-08-17$ & $07: 13$ & 2.9 & 10 & 16 \\
$2000-11-13$ & $16: 30$ & 3.2 & 10 & 15 \\
$2001-02-23$ & $22: 19$ & 3.6 & 8 & 6 \\
$2001-03-17$ & $00: 29$ & 3.4 & 7 & 18 \\
$2001-04-06$ & $02: 22$ & 3.6 & 16 & 15 \\
$2001-07-09$ & $22: 49$ & 3.1 & 5 & 12 \\
$2001-07-17$ & $15: 06$ & 4.9 & 5 & 5 \\
\hline
\end{tabular}


to $M_{\mathrm{w}}$. Waveforms recorded on hard rock sites are inspected visually and transformed to ground velocities in $\mathrm{m} / \mathrm{s}$. To compare these data with the previously obtained excitation terms in the time domain, we filter them using a Butterworth 8-pole band pass filter with corner frequencies of $0.707 f_{k}$ and $1.414 f_{k}$. Peak amplitudes after the S- arrival are normalized with the empirical attenuation functional (Bay et al., 2003) to 40 $\mathrm{km}$ hypocentral distance and averaged for each event.

In Figure $7 \mathrm{a}, \mathrm{b}$ we plot the excitation terms of these events at two selected frequencies $(2 \mathrm{~Hz}$ and $15 \mathrm{~Hz}$ ) as gray dots (D2). The excitation terms obtained by Bay et al. (2003) from the inversion of short period data are shown as black dots (D1). To confirm the validity of the $M_{\mathrm{w}}$ transformation applied to the short period data $\left(M_{\mathrm{w}}=M_{\mathrm{L}}-0.2\right)$, we compare the least square fit of the inverted excitation terms (black dashed line; LSQR D1) for which $M_{\mathrm{L}}$ is converted to $M_{\mathrm{w}}$ according to Braunmiller et al. (2005) with the least square fit of the broadband data (gray dashed line; LSQR D2). Good agreement between the two lines suggests that the magnitude conversion is also valid for data that are not included in Braunmiller's $M_{\mathrm{w}}-M_{\mathrm{L}}$ regression.

To evaluate how the models $A_{0}$ and $Y_{1}$ compare with the observed broadband amplitudes over the entire magnitude range of interest, we overlay in Figure 7 models $A_{0}$ (thin black line) and $Y_{1}$ (thick black line). We find that $A_{0}$ fits the amplitudes between $3.0 \leq$ $M_{\mathrm{w}} \leq 4.0$ well at $2 \mathrm{~Hz}$ and under-predicts the amplitudes $M_{\mathrm{w}}>4.0$ and at $15 \mathrm{~Hz} . Y_{1}$ over predicts the amplitudes for $M_{\mathrm{w}}>4.0$ at $1 \mathrm{~Hz}$ and under-predicts the amplitudes at $15 \mathrm{~Hz}$ over the entire magnitude range.

\section{Prediction of ground motion}

\section{Epistemic uncertainty}

The aforementioned sensitivity analysis demonstrates that a range of models fit the data almost equally well. Since our data set contains just small to moderate size events, scaling to higher magnitudes will generate a large epistemic uncertainty and has to be evaluated carefully.

The best fitting model found in this study, $A_{0}$, has a $\Delta \sigma$ of 2.7 bars, $\kappa_{0}=0.025$ and $Q(f)=270 f^{0.50}$. Compared to hazard related studies, which are derived mainly from large events (e.g, Ide and Beroza, 2001; Maeda and Walter, 1996), a $\Delta \sigma$ of 2.7 bars is low and leads to unreasonably low amplitudes for large events.
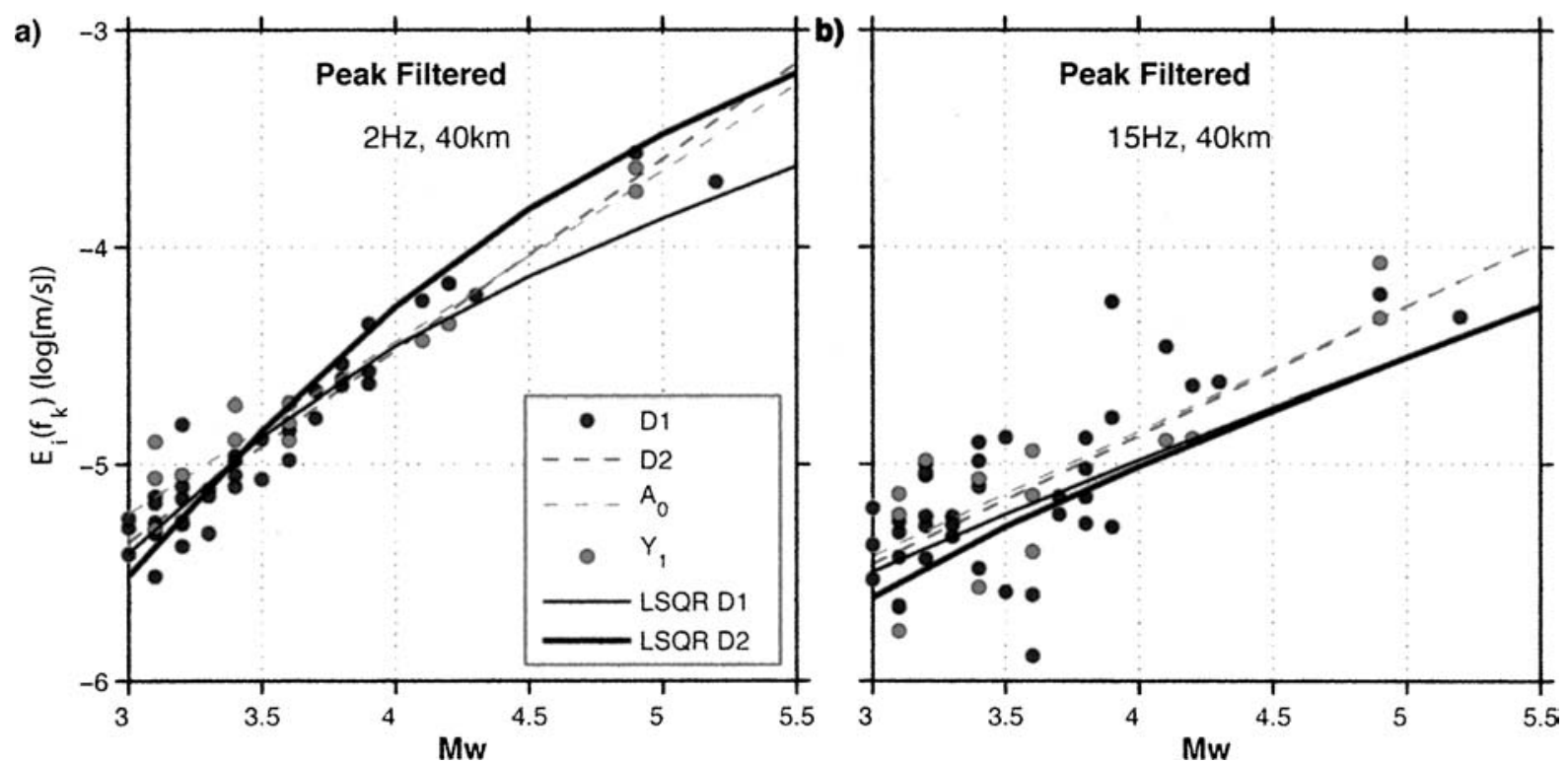

Figure 7. Excitation of ground motion at $40 \mathrm{~km}$ hypocentral distance for peak filtered amplitudes at $2 \mathrm{~Hz}$ (a) and $15 \mathrm{~Hz}$ (b). Black dots mark excitation terms used in this study to calibrate the theoretical models. The black dashed line shows the corresponding linear least square fit. Gray dots mark average amplitudes, normalized to $40 \mathrm{~km}$, obtained from analyzing independently estimated broadband data on 15 events recorded after Nov. 1999. For these events, independent $M_{\mathrm{w}}$ estimations exist. The gray dashed line shows the corresponding linear least square fit. Model $A_{0}$ (thin black line) is the theoretical excitation term computed with $G\left(r_{\text {ref }}\right)=40^{-1.1}, Q(f)=270 f^{0.5}, \kappa_{0}=0.0125$ and $\Delta \sigma=2.7$ bars. A thick black line indicates the theoretical excitation term model $Y_{1}\left(G\left(r_{\text {ref }}\right)=40^{-1.2}, Q(f)=440 f^{0.37}, \kappa_{0}=0.043 \Delta \sigma=24\right.$ bars $)$. 
A number of damaging earthquakes have occurred in Switzerland in historic times, especially the 1356 Basel event. The EMS98 (Gruenthal, 1998) distributions of these events, reaching intensity IX, is difficult to explain by stress drops in the 3 bar range, even considering site amplification. Therefore, we conclude that model $A_{0}$ cannot be extrapolated for computing ground motions of larger $\left(M_{\mathrm{w}}>4.0\right)$ events. The scaling for larger magnitudes must differ from what we observe for smaller events.

To constrain the range of ground motion estimates at higher magnitudes, we integrate results from scaling studies by Mayeda and Walter (1996) and Ide and Beroza (2001). These two studies are selected because each assesses a wide range of magnitudes and represents different classes of models. Mayeda and Walter (1996) propose that in California apparent stress, $\sigma_{\mathrm{a}}$, is proportional to $M_{0}^{0.25}$. In contrast Ide and Beroza (2001) propose a constant stress drop model with a logarithmic mean $\sigma_{\mathrm{a}}$, of about 10 bars. Their model is based on a compilation of worldwide studies and finds a constant stress drop over 17 orders of seismic moment.

Different from Brune's stress drop $\Delta \sigma$ (required by the stochastic ground motion model) Mayeda and Walter (1996) and Ide and Beroza (2001) compute the apparent stress, $\sigma_{\mathrm{a}}$. Because $\Delta \sigma$ and $\sigma_{\mathrm{a}}$ are believed to be related by a constant factor (Hough, 1996) their scaling behavior is comparable. However, the actual scaling factor is unknown, because the methods applied to derive stress drop are different. We now evaluate if this stress drop scaling can be applied to our study. To perform such an evaluation we use 98 waveforms of arbitrarily selected Californian moderate size events $\left(3.4 \leq M_{\mathrm{w}} \leq 5.6\right)$, recorded by TRINet between January 1999 and December 2001. These waveforms are downloaded from the online database provided by the Southern Californian Earthquake Data Center (SCEDC). Data are transformed to ground velocities in $(\mathrm{m} / \mathrm{s})$ and filtered applying a Butterworth 8pole band pass filter with corner frequencies of $0.707 f_{k}$ and $1.414 f_{k}$. Peak amplitudes are normalized to $40 \mathrm{~km}$ hypocentral distance by applying the attenuation model for California (Raoof et al., 1999). Stations are limited to sites with average $30-\mathrm{m}$ shear wave velocities, $V_{30}$, ranging between 519 and $760 \mathrm{~m} / \mathrm{s}$ (Wills et al., 2000).

To compute excitations for the two models, we transform $\sigma_{\mathrm{a}}$ into $\Delta \sigma$, using a proportionality factor of 3.3; the average between the two factors proposed in the literature (Singh and Ordaz, 1994; Andrews, 1986). Therefore, for Mayeda and Walter (1996), we obtain a $\Delta \sigma$ ranging between 7 bars at $M_{\mathrm{w}}=3.0$ to 143 bars at $M_{\mathrm{w}}=6.5$. For the model based on Ide and Beroza (2001), $\Delta \sigma \cong 30$ bars. To propagate the ground motion to $40 \mathrm{~km}$ hypocentral distance we apply the attenuation model developed by Raoof et al. (1999). Figure 8 compares the observed ground excitations in California $\left(\mathrm{Cal}_{\text {data }}\right)$ and the two model forecasts $\mathrm{Cal}_{\text {inc }}$ and $\mathrm{Cal}_{30}$ for $\Delta \sigma \propto M_{0}^{0.25}$ and $\Delta \sigma \cong 30$ bars, respectively.

We observe that both models fit the data of moderate Californian events equally well in the magnitude range for which we have observations. This gives us confidence that both models can be employed to develop ground motion models. For comparison, we also show in Figure 8 the range of ground motion excitation (light gray area) based on the same attenuation but with a $\Delta \sigma 50$ to 100 bars as used by Hanks and McGuire (1981), Boore (1983) and Silva and Darragh (1995).

We propose two predictive ground motion models for Switzerland that express epistemic uncertainty in ground motion scaling for larger magnitudes. These models assume that small to moderate size earthquakes can be used to constrain attenuation parameters, but can not provide information about $\Delta \sigma$ for large events. Both models use the $G(r), Q(f)$ and $\kappa_{0}$ from model $A_{0}$. The first model $A_{\text {inc }}$ adopts the $\Delta \sigma \propto M o^{0.25}$ scaling relation of Mayeda and Walter (1996). The second, alternative model $A_{30}$ assumes a constant $\Delta \sigma \cong 30$ bars as found by Ide and Beroza (2001). Figure 10 plots the stress drops of both models as a function of magnitude. The model parameters are listed in Table 1 and compared to the Swiss data in Figure 9. From Figure 9 we see that both models predict similar amplitudes at high magnitudes, but that only model $A_{\text {inc }}$ agrees with the amplitudes of small events. To allow a direct comparison between Californian and Swiss amplitudes, we plot in Figure 9 also the 50-100 bar range of Californian ground motion excitation (light gray area) computed with the same parameters as in Figure 8.

\section{Aleatory uncertainty}

Aleatory uncertainty includes parametric and modeling uncertainties. Parametric uncertainty, $\sigma_{\text {lg }}$ accounts for event-to-event variations due to source, path and site properties. The modeling uncertainty, $\sigma_{\mathrm{lg}}$,model, is determined from the misfit between modeled ground motion data and recorded data; the include residuals due to physical processes not included in the model (EPRI, 1993; Toro et al., 1997):

$$
\sigma_{\lg }=\sqrt{\sigma_{\lg , \text { model }}^{2}+\sigma_{\lg , Q(f), G(r), \Delta \sigma, \kappa_{0}}^{2}}
$$




\section{CALIFORNIA}

a)

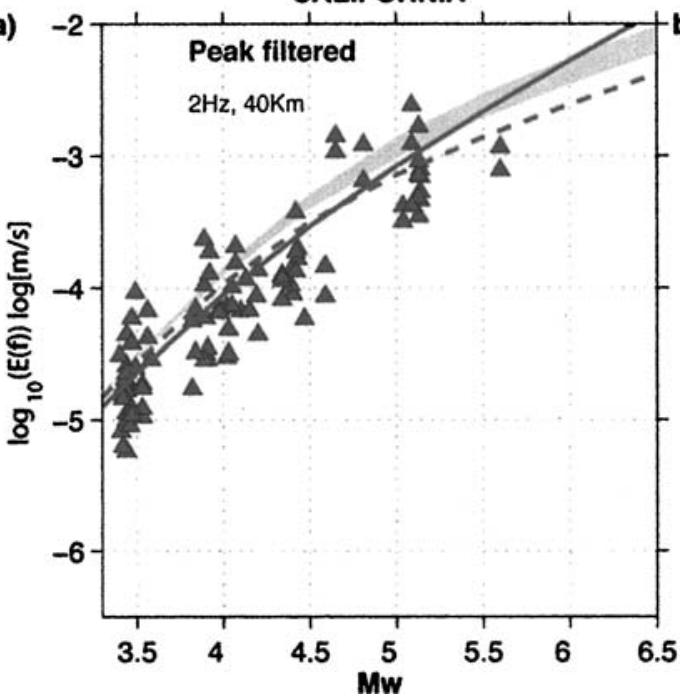

CALIFORNIA

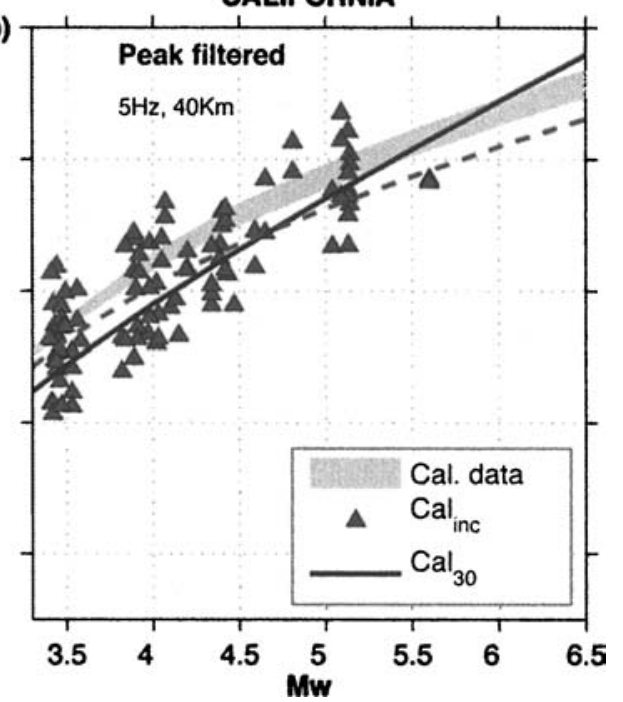

Figure 8. Comparison between theoretical excitation terms as a function of magnitude and Californian broadband data recorded by TRINet. Seismograms are peak filtered at $2 \mathrm{~Hz}$ (a) and $5 \mathrm{~Hz}$ (b), normalized to $40 \mathrm{~km}$ hypocentral distance, and plotted as a triangle at their respective magnitude. Predictive ground motion models are computed with the attenuation derived by Raoof et al. (1999), assuming a constant $\Delta \sigma=30$ bars (dashed line) and an increasing $\Delta \sigma \propto M_{0}^{0.25}$ (solid line). The light gray area outlines the range of ground motion amplitudes computed with a $\Delta \sigma$ ranging from 50 to 100 bars.
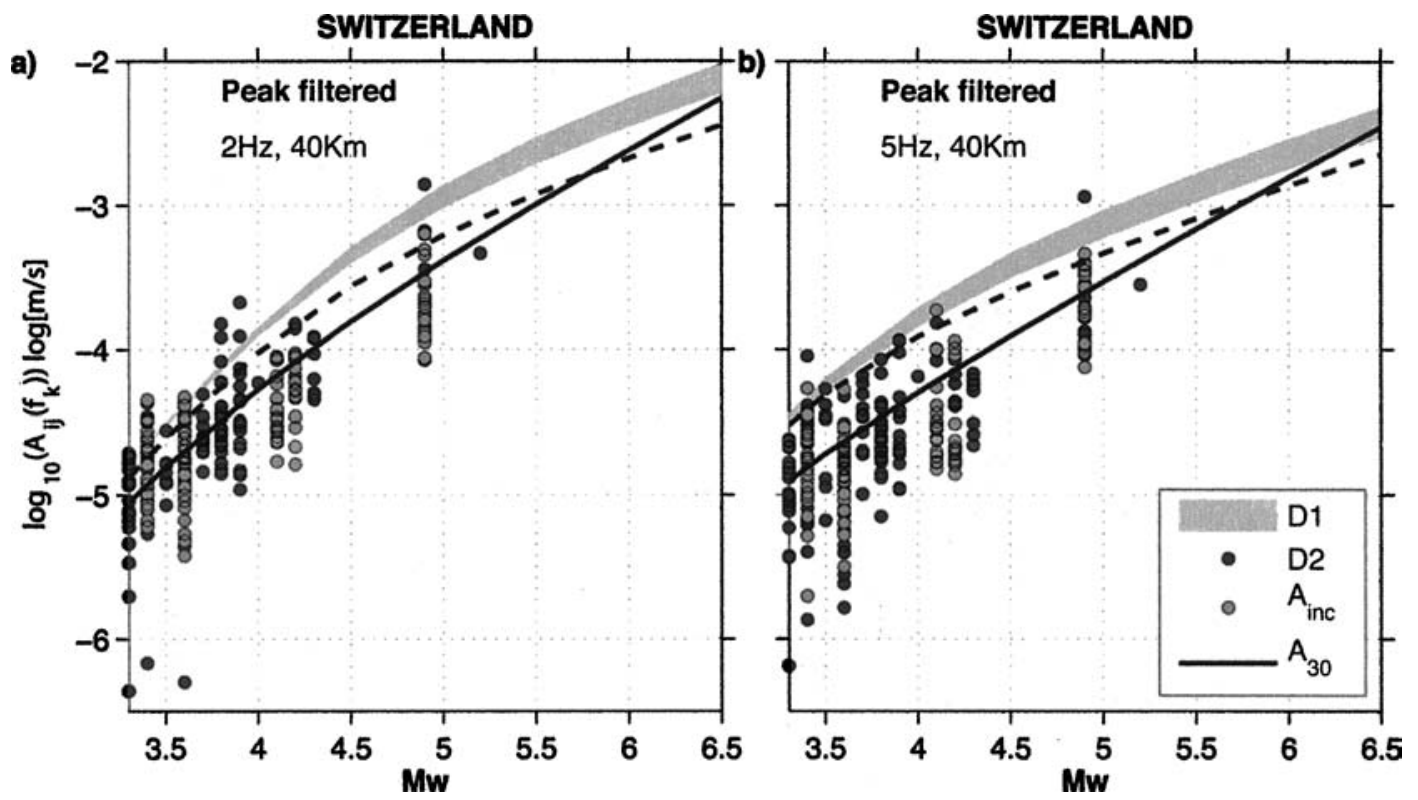

Figure 9. Comparison between theoretical excitation terms as a function of magnitude, Swiss short period data D1 (black dots) and broadband data D2 (gray dots). Broadband data D2 are peak filtered at $2 \mathrm{~Hz}$ (a) and $5 \mathrm{~Hz}$ (b) and normalized to 40 km hypocentral distance. Predictive ground motion models are computed with a constant $\Delta \sigma=30$ bars, $A_{30}$ (dashed line) and increasing $\Delta \sigma \propto M_{0}^{0.25}, A_{\text {inc }}$ (solid line). For comparison the range of amplitudes for Californian events computed with a $\Delta \sigma 50$ to 100 bars in Figure 8 (light gray area) is shown.

The estimated average $\sigma_{\lg }(1 \mathrm{~Hz}$ to $15 \mathrm{~Hz})$ is based on both the logarithm of model $A_{0}$ and data from events in the magnitude range $3.0 \leq M_{\mathrm{w}} \leq 4.0$ and distance range $10 \leq r \leq 300 \mathrm{~km}$. Dividing data further is not sensible, because results would not be statistically significant due to small sample sizes. We restrict the magnitude range to $3.0 \leq M_{\mathrm{w}} \leq 4.0$ for two reasons: model $A_{0}$ is primarily derived from data of 
that range and uncertainty in stress drop scaling would otherwise influence $\sigma_{\mathrm{lg}}$. We compute an average $\sigma_{\mathrm{lg}}$ of 0.35 .

\section{Evaluation of the significance of site regionalization}

The relative site term listed in Eq. (2), $V_{j}\left(f_{k}\right)$ measures at each station how the observed seismic spectra derivate from the mean (Figure 2d). This term is mainly caused by amplification due to differences in the physical properties of shallow geology at the recording site. Rock sites in the Foreland are preferably NEHRP (1994) class B (750 to $1500 \mathrm{~m} / \mathrm{s})$, whereas alpine sites are mostly class A, with shear wave velocities of $>1500$ $\mathrm{m} / \mathrm{s}$ (Fäh et al., 2003). In our inversion, the sum of all site-terms is constrained to zero for each frequency. Figure 2d shows each station's deviation from the average site condition plotted against frequency as derived in Bay et al. (2003). Sites in the Alpine Foreland are gray; sites in the Alps are black. Average site terms for frequencies ranging from 1 to $15 \mathrm{~Hz}$ are plotted for each station in Figure 1. Blue triangles indicate negative deviations, red triangles are positive. The size of the triangles is proportional to the absolute value of the site term. As we can derive from Figures 1 and $2 d$, we see a clear regional clustering, with $V(f)_{\text {Foreland }}>0$ and $V(f)_{\text {Alps }}<0$. Computing the average $V(f)$ in the respective two regions results in a factor of up to 1.9 higher amplitudes in the Foreland (Table 1).

Based on the visual inspection of Figures. 1 and $2 \mathrm{~d}$, the proposed correlation between geology and site residual is reasonable when considering surface geology. However, such a correlation could also arise by chance. To evaluate whether the differences in $V(f)$ between Alps and Foreland are indeed statistically significant, we design a test based on a Monte Carlo Simulation, because it makes no assumption about sample size and shape of the distribution. We create 10000 random permutations of the individual sites terms, $V_{j}(f)$. For each permutation new simulated $V(f)_{\text {Foreland }}$ and $V(f)_{\text {Alps }}$ are computed. The boundary between the two regimes is derived from independent geological data (Geological map of Switzerland, 1:50000), not from the site terms themselves. The resulting histograms are plotted in Figure 11 and compared to the observed $V(f)_{\text {Foreland }}$ and $V(f)_{\text {Alps }}$ (triangles). Also marked are the 0.5 and 99.5 percentiles (dashed lines). From Figure 10c,d, and a similar analysis for the remaining frequencies, we conclude that the probability is less than $0.5 \%$ that the observed amplification in the Foreland is a by-chance occurrence. Deamplification in the Alps (Figure 10a,b),

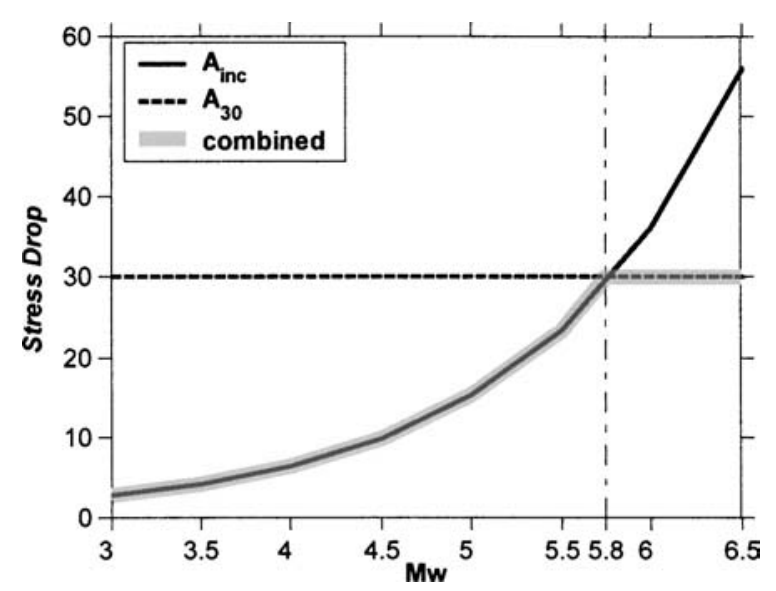

Figure 10. Stress drop as a function of magnitude for models $A_{\text {inc }}$ (thick black solid line) and $A_{30}$ (thick black dashed line). The thick gray line combines both models.
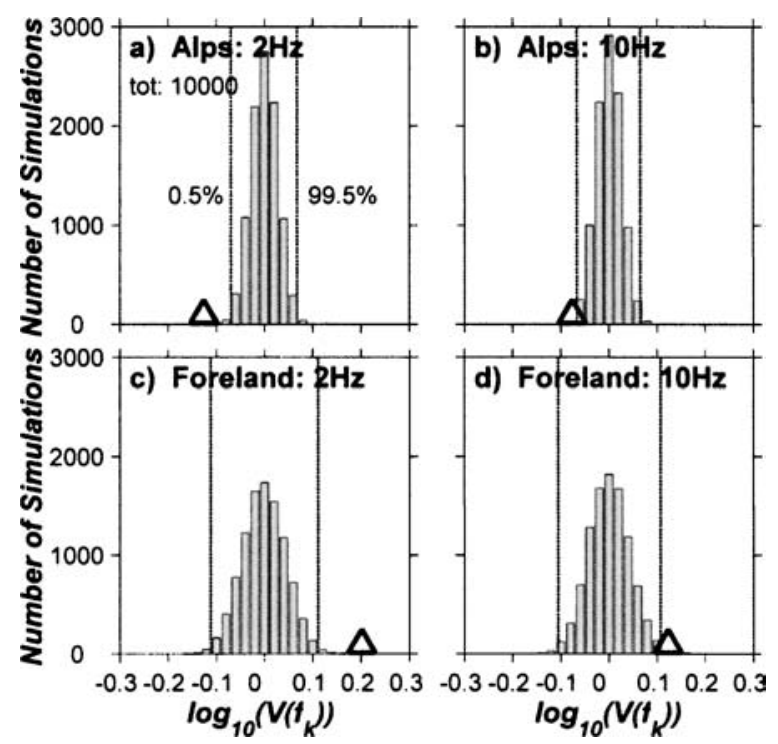

Figure 11. Histograms of simulated mean site terms $\log _{10} V\left(f_{k}\right)_{\text {Foreland }}$ and $\log _{10} V\left(f_{k}\right)_{\text {Alps }}$, obtained from $10 \quad 000$ random simulations of the observed site terms. Shown are results for the Alps (top frames) and the Alpine Foreland (bottom frames) at $2 \mathrm{~Hz}$ (left frames) and $10 \mathrm{~Hz}$ (right frames). The 0.5 and 99.5 percentiles are indicated (dashed lines). Black triangles mark the actual observed mean site residuals.

compared to the mean site, is generally smaller, but also is statistically significant. Consequently, we introduce frequency-dependent site amplification factors, ranging from 1.29 to 1.6 for rock sites in the Alpine Foreland, and from 0.75 to 0.85 for rock sites in the Alps (Table 1). 

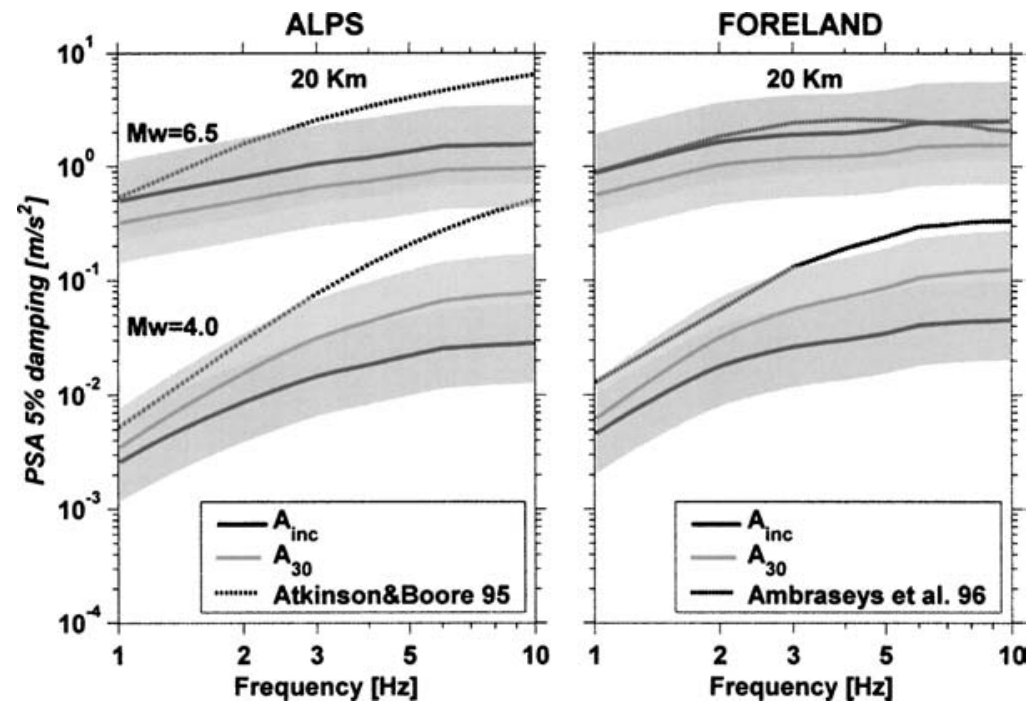

Figure 12. Pseudo spectral accelerations, PSA, 5\% damping at $20 \mathrm{~km}$ hypocentral distance, $M_{\mathrm{w}}=4$ and 6.5 . Swiss ground motion models are computed with increasing stress drop, $A_{\text {inc }}$ (black solid lines) and a stress drop of 30 bars, $A_{30}$ (gray solid lines). Predictions for an Alpine NEHRP (1994) A site (a) are compared to an Eastern North American ground motion relation (Atkinson and Boore, 1995; black dashed lines). Predictions for a Foreland NEHRP (1994) B site (b) are compared to a European ground motion relation at $M_{\mathrm{w}}=6.5$ (Ambraseys et al., 1996; black dashed lines).
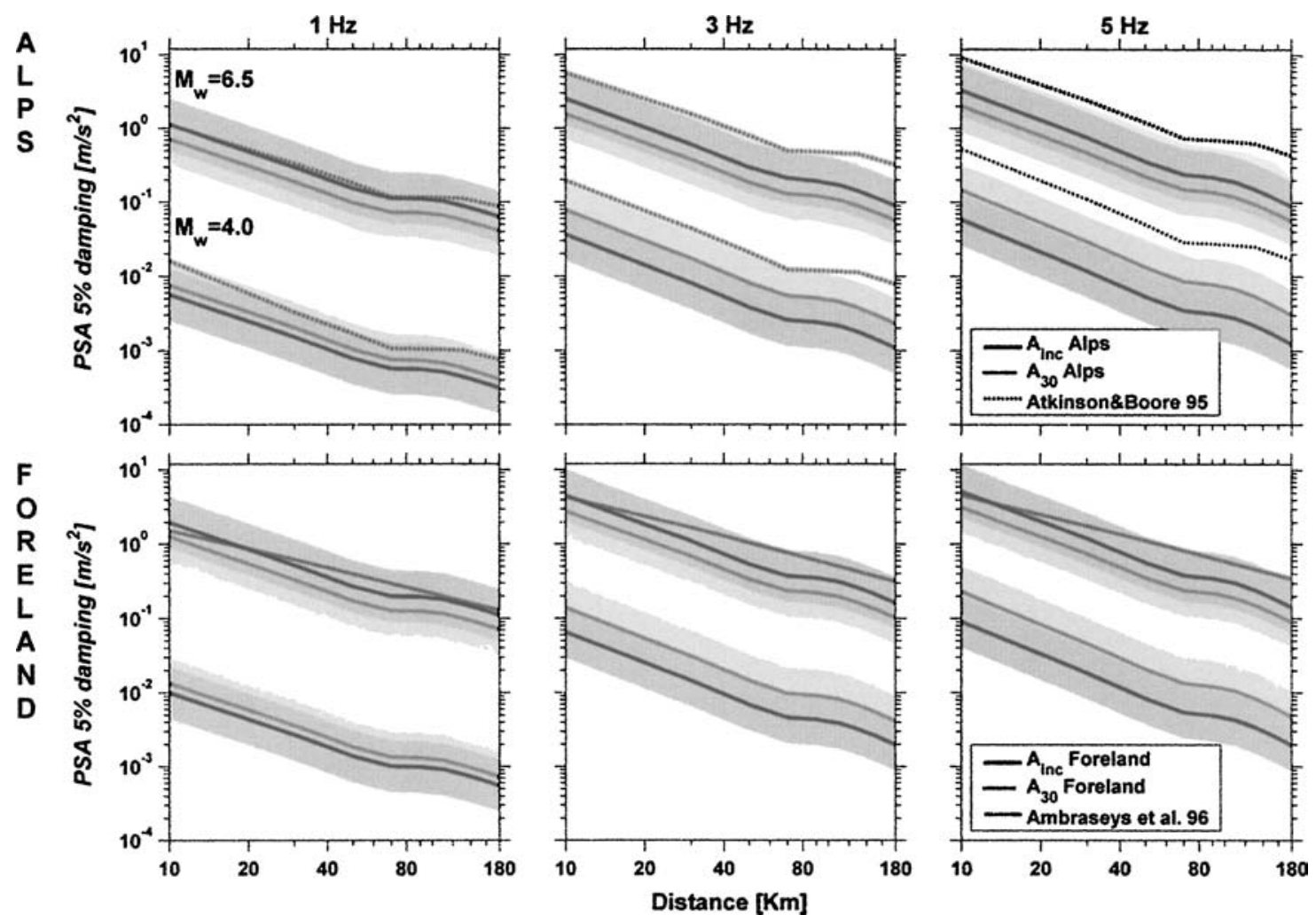

Figure 13. Pseudo spectral accelerations, PSA, $5 \%$ damping at $1 \mathrm{~Hz}, 3 \mathrm{~Hz}$ and $5 \mathrm{~Hz}, M_{\mathrm{w}}=4$ and 6.5. Swiss ground motion models are computed with increasing stress drop, $A_{\text {inc }}$ (black solid lines) and a stress drop of 30 bars, $A_{30}$ (gray solid lines). Predictions for an Alpine NEHRP (1994) A site (top frames) are compared to an Eastern North American ground motion relation (Atkinson and Boore, 1995; black dashed lines). Predictions for a Foreland NEHRP (1994) B site (bottom frames) are compared to a European ground motion relation at $M_{\mathrm{w}}=6.5$ (Ambraseys et al., 1996; black dashed lines). 


\section{Comparison with other ground motion estimates}

We now compare the Swiss ground motion model with other models. Models $A_{\text {inc }}$ and $A_{30}$ combined with their respective aleatory uncertainty define a range of viable ground motion estimates for Switzerland. Site differences between rock sites in the Alps and the Foreland are considered by a frequency-dependent site amplification factor. The horizontal component is derived from the vertical by applying an $\mathrm{H} / \mathrm{V}$-factor, on average 1.3. This factor is the ratio between the horizontal and vertical site terms. All values needed to predict ground motion by applying the computer codes SMSIM (Boore, 2001) are listed in Table 1. Figure 12 shows PSA, 5\% damping, for an average Alpine rock site in a) and for the Foreland in b) versus frequency at a hypocentral distance of $20 \mathrm{~km}$ and as a function of distance at $1 \mathrm{~Hz}, 3 \mathrm{~Hz}$ and $5 \mathrm{~Hz}$ (Figure 13). Figures 12a and 13 (top frame) compares our results on alpine property to Eastern North American Ground motion estimates (Atkinson and Boore, 1995) at $M_{\mathrm{w}}=4.0$ and
$M_{\mathrm{w}}=6.5$. As we can see, the Eastern North American predictions are much higher than the Swiss, especially for high frequencies, but the attenuation with distance is similar. In Figures 12b and 13 (bottom frames) we compare our results of the Alpine Foreland to a European ground motion relationship (Ambraseys et al., 1996) at $M_{\mathrm{w}}=6.5$ (the European ground motion relation is valid for $M_{\mathrm{s}}>4.0 ; M_{\mathrm{w}}>4.8$ respectively). As we see from both figures, the European predictions are slightly higher than the Swiss and the difference increases with increasing distance (Figure 13b). This suggests the existence of differences in attenuation between the regions, unless methodological differences could offer an explanation.

\section{Implications for probabilistic seismic hazard}

The ultimate use of predictive ground motion models lies in estimating probabilistic or deterministic seismic hazard. Therefore, we consider it important to evaluate the implications of the two ground motion models,
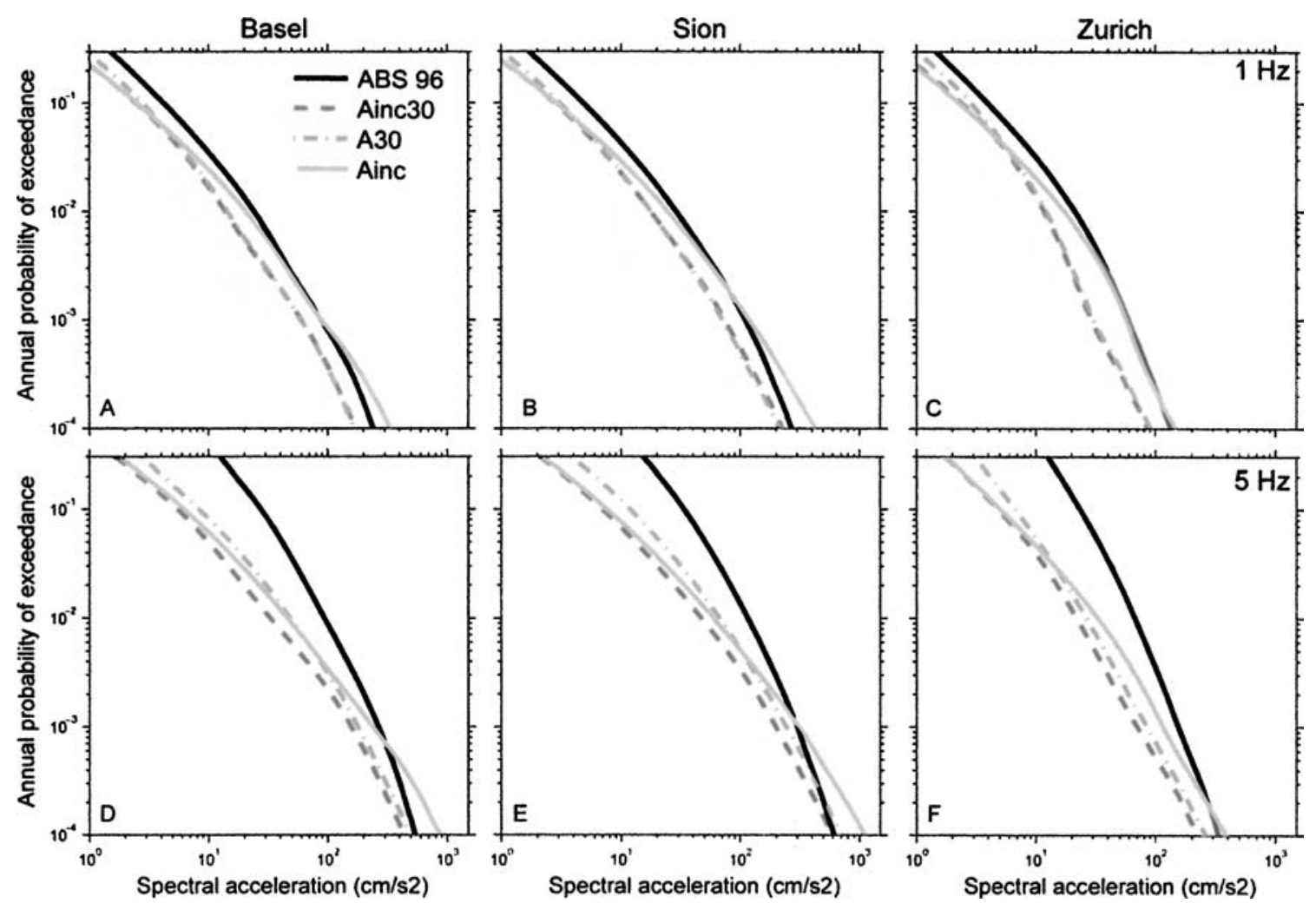

Figure 14. Hazard curves for three cities in Switzerland (Basel, Sion and Zurich) and two frequencies (Top: $1 \mathrm{~Hz}$; bottom: $5 \mathrm{~Hz}$ ). Plotted is the median annual probability of exceedance as a function of pseudo-spectral acceleration with $5 \%$ damping in ( $\left.\mathrm{cm} / \mathrm{s}^{2}\right)$. The hazard is compute during the SED 2004 hazard model (Wiemer et al., 2005). Four different attenuation models are used: Ambraseys et al. (1996), increasing stress drop to 30 bar, constant 30 bar stress drop, and increasing stress drop (see Figure 1). 
$A_{\text {inc }}$ and $A_{30}$ for Switzerland. We compute probabilistic seismic hazard (PSH) curves at representative sites at 1 and $5 \mathrm{~Hz}$ for PSA, 5\% damping and $\sigma_{\mathrm{lg}}=0.35$, assuming a foreland site. The Swiss Seismological Service released a new probabilistic seismic hazard model for Switzerland in November of 2004 (Wiemer et al., 2005). The model applies a Monte-Carlo type approach to computing hazard, based on a simple logical of 24 branches (two zoning models. two completeness models, three rate estimation models and two Mmax models). Seismicity rates are derived from a recently compiled moment magnitude catalog (Fäh et al., 2003) ranging from 1300 to 2000 A.D.

We use the SED 2004 hazard model to study the impact of the different attenuation models developed in this study. In Figure 14, we show the median hazard curves for two frequencies $(1 \mathrm{~Hz}$ and $5 \mathrm{~Hz})$ and two regions (Basel, being an area of higher hazard, and Zurich, a site with lower hazard). We compare four different attenuation models: Ambraseys et al. (1996), increasing stress drop to $30 \mathrm{bar}$, constant 30 bar stress drop, and increasing stress drop (see Figure 10). Results show that Ambraseys et al. (1996) is consistently higher than the models derived specifically for Switzerland. This is particularly obvious for $5 \mathrm{~Hz}$ (Figure 14D-F) and high probabilities of exceedance $\left(>10^{-2}\right)$. This difference narrows for longer return periods or lower probability levels; below $10^{-3}$, the SED models are quite comparable, sometimes higher, than European model.

\section{Discussion and conclusions}

The main result of this study is a spectral model of ground motions and its uncertainty for Switzerland (Figures 12 and 13, Table 1). Our model is based on the most comprehensive and detailed study of spectral ground motion yet conducted for Switzerland. It can be readily applied to determine design ground motions and to evaluate seismic hazard (Figures 14 and $15)$. We propose two ground motion models, $A_{\text {inc }}$ and $A_{30}$ that express epistemic uncertainty when extrapolating to large magnitudes. These two models, and their associated aleatory uncertainty, embody the range of predictive ground motion estimates in Switzerland for $3.0 \leq M_{\mathrm{w}} \leq 6.5$ and distances ranging between 10 and $300 \mathrm{~km}$ hypocentral distance. Table 1 summarizes the model parameters needed to predict spectral ground motion in terms of response spectral displacement, pseudo spectral velocities and PSA in conjunction with the stochastic approach (Boore, 1983, Boore 2001, 2003).
Stress drops found in this study for the magnitude range $3.0 \leq M_{\mathrm{w}} \leq 5.2$ are generally below 10 or below 30 bars, depending on how the attenuation is parameterized (Figure 6). Results are similar to a Norwegian study (Kvamme et al., 1995) located in a similar tectonic regime and with similar average site properties and magnitude and distance range. Kvamme et al. (1995) found $\Delta \sigma$ to be below 10 bars mainly, slightly increasing with magnitude. Their study is based on about 200 Scandinavian events. Our results, however significantly differ from comparable studies in Eastern North America and California. Atkinson (1993), for example, computed a logarithmic-mean high frequency stress parameterof 120 bars for Eastern North America.

We must conclude that magnitude $3.0 \leq M_{\mathrm{w}} \leq 5.0$ size earthquakes in Switzerland cannot be explained by large stress drops of 50 bars and above (Figure 9). We consider the low stress drop of the investigated earthquakes a key result, especially since our study is the first to estimate stress drop in Switzerland. There are a number of possible reasons for the deviation from studies in other regions, which are listed below:

1. Tectonic differences, such as the much lower strain rates in Switzerland and fault mechanism. Choy and Boatwright (1995) and Perez-Campos and Beroza (2001) find that the apparent stresses of large strikeslip events are consistently higher than those of dipslip events.

2. Differences in site characterization. Sites considered in this study are bedrock locations of NEHRP (1994) site class A and B. For Italy Cocco and Rovelli (1989) proposed a variation of the Brune stress parameter of 100 to 900 bars, without considering site amplifications. In contrast, Margaris and Boore (1998) have shown the importance of the site amplification, reducing the derived stress parameter up to 7 to 8 times. Basin depths and their 3-dimensional effects further influence site effects (e.g., Field et al., 2000). In addition, strong motion sites are generally operated in triggered mode, which can lead to a statistical bias due to selective sampling of only the strongest recordings (Bay et al., 2003). The combination of these effects might lead to overestimating stress drop in some studies that rely on strong ground motions.

3. Differences in scaling between small and large events and magnitude dependent stress drop. Many observed ground motion characteristics of Californian earthquakes $(M>4.0)$ have been described successfully through a Brune model with $\Delta \sigma$ in 
the range of 50 to 100 bars, in conjunction with the stochastic approach (e.g., Hanks and McGuire, 1981; Boore, 1983; Silva and Darragh, 1995; Boore and Joyner, 1997). Nevertheless, the Californian data evaluated for comparison here (Figure 8), which cover the same magnitude range as the Swiss data, and are in better agreement with a $\Delta \sigma \cong 30$ bars as derived from Ide and Beroza (2001) or an $\Delta \sigma$ increasing approximately as $M_{0}^{0.25}$ (Mayeda and Walters, 1996). Our results (Figure 8) agree with Raoof et al. (1999), who show that a $\Delta \sigma$ of 70 bars over-predicts the amplitudes of Californian events ranging between $4.0 \leq M_{\mathrm{w}} \leq 6.0$ at frequencies $>1 \mathrm{~Hz}$.

We believe that, although arguments 1 and 2 might contribute, differences in scaling (argument 3) are most important in explaining ground motions of larger events. Further evidence is that the best fitting model, $A_{0}$ and the model with the highest $\Delta \sigma, Y_{1}$ (Figure 4) are not able to predict the entire magnitude and frequency range satisfactorily (Figure 7). Both models underpredict the amplitudes of larger events and higher frequencies.

Functional dependence between seismic moment and stress drop is an unresolved issue of many studies. Many researchers find that stress drop is independent of earthquake size (e.g. Aki, 1972; Kanamori and Anderson, 1975; Ide and Beroza, 2001). In contrast, Kanamori et al. (1993), Mayeda and Walter (1996), Nuttli (1983a,b) and Boatwright and Choy (1992) observe an increase in stress drop with moment. Mai and Beroza (2000) suggest that dip-slip events $(5.5 \leq$ $M_{\mathrm{w}} \leq 8.0$ ) follow self-similar scaling, unlike strikeslip events in the same magnitude range for which they find evidence of increasing stress drop with moment. Common to all studies of various types of stress drop, is the observation that the considerable scatter in stress drop cannot readily be explained by seismotectonical parameters such as tectonic regimes, focal mechanisms, depths, strain rates etc.. Our results show a similar scatter in stress drops for individual quakes (Figure 6). This introduces significant uncertainty when one has to extrapolate appropriate scaling from small events. We are not able to decide how stress drop scales with magnitude and we conclude that our magnitude range is too small to find a definitive answer (Figure 6). Therefore, we propose two models, $A_{\text {inc }}$ and $A_{30}$. Both are based on the attenuation parameter found here but differ in assuming how stress drop scales with magnitude. $A_{\mathrm{inc}}$ assumes a $\Delta \sigma$ increasing approximately as $M_{0}^{0.25} ; A_{30}$ is computed with $\Delta \sigma \cong 30$ bars. With a logic tree approach, both models can be weighted differently, depending on the magnitude. For the magnitude range of observations $\left(3.0 \leq M_{\mathrm{w}} \leq 5.2\right)$ we suggest giving a higher weight to model $A_{\text {inc }}$, because it fits our data (Figure 9). If a logic tree approach is not used to compute seismic hazard, an alternative is to combine both models by taking always that which gives us the smallest value (Figure 10 thick gray line). This means that $A_{\text {inc }}$ is captured at $M_{\mathrm{w}} 5.8$ by $A_{30}$.

Site amplification as function of frequency, $V(f)$, is an important factor contributing to hazard. Several studies have shown that developing accurate regional predictive site amplification models is difficult without detailed knowledge of shallow shear wave velocities (Field et al., 2000). However, shear wave velocities currently exist for only a few sites in Switzerland (e.g., city of Basel, Kind et al., 2002). Given the tectonic setting of Switzerland (Alps and the Alpine Foreland) differences in site amplifications are observed. To evaluate whether a regionalization into Alps and Foreland gives statistically significant predictions, we performed a novel test based on the Monte Carlo simulation method to determine the statistical significance of our site parameterization. We find that the probability of the Foreland amplification being random is less than $0.5 \%$ (Figure 10c,d). Consequently, we introduce frequency dependent site amplification factors, ranging from 1.3 to 1.6, for Foreland rock sites, and from 0.75 to 0.85 for Alpine rock sites (Table 1). At sites for which amplification factors exist, like Basel (Kind et al., 2002) the values can be integrated in the stochastic model of ground motion.

We compare our predictive ground motion relation to a European (Ambraseys et al., 1996) and an eastern North American (Atkinson and Boore, 1995) ground motion scaling (Figures 12 and 13). The latter predicts significantly higher ground motions in the magnitude range $4.0 \leq M_{\mathrm{w}} \leq 6.5$, a finding which can be explained by the high stress drop found for earthquakes there. Differences between the Swiss and the European ground motion scaling can be explained by the fact that Ambrasey et al.'s study is based on a dataset of mostly Mediterranean earthquakes. Comparatively lower ground motions in the Alpine Foreland agree well with a study by Wössner et al. (2002), who computed synthetic ground motions of $M_{\mathrm{w}}=6$ earthquakes in the Upper Rhinegraben using empirical Green's functions. They found that Ambrasey et al.'s ground motion relation conservatively estimates the ground motion in their investigated region and for the considered earthquake size. 
When computing probabilistic seismic hazard (Figure 14), the difference between the Swiss specific models and the European one by Ambrasey et al. (1996) are highly significant only for higher frequencies and annual exceedance probabilities above $10^{-2}$. Here, smaller magnitudes $(M<5)$ are contributing most of the hazard, and the Swiss specific models predict lower amplitudes (Figure 12). In addition, there are several systematic differences between our study and Ambrasey et al. (1996). First of all, the site class of Ambraseys is quite different, his reference rock has a shear wave velocity in the upper $30 \mathrm{~m}$ that is about half of the $1500 \mathrm{~m} / \mathrm{s}$ estimated for our sites. Secondly, Ambraseys based his study on Ms estimates, while we use Mw. The conversion applied to related the two are specifically unreliable for smaller $(M<5.5)$ events, where Ms is not well measurable. Lastly, the majority of Ambraseys earthquakes stem from the Mediterranean area, a tectonic environment quite different from Switzerland.

From the observed difference in hazard which results from using different predictive ground motion model (Figure 14) we conclude that region specific attenuation and scaling studies are highly important for regional hazard assessment.

\section{Acknowledgements}

The authors would like to thank L. Malagnini, S. Sellami, P. Suhadolc, J. Braunmiller, N. Deichmann, F. Kind, D. Roten, A. Wyss, S. Steimen and E. SpühlerLanz for helpful discussions and comments as well as software support. R. Herrmann and D. Boore are especially thanked for providing their software. We thank the SED for providing the ground motion data. We are grateful to K. Jackson for greatly enhancing the manuscript. Two anonymous reviewers are thanked for critical comments that allowd us to improve the manuscript. This article is contribution number 1402 of the Geophysical Institute of ETH Zurich.

\section{References}

Aki, K., 1972, Earthquake mechanism, Tectonophysics 13, 423-446. Ambraseys, N.N., Simpson, K.A. and Bommer, J.J., 1996, Prediction of horizontal response spectra in Europe, J. Earthq. Eng. and Struct. Dyn. 25, 371-400.

Anderson, J.G. and Hough, S.E., 1984, A model for the shape of the Fourier amplitude spectrum of acceleration at high frequencies, Bull. Seism. Soc. Am. 74, 1969-1993.

Andrews, D.J., 1986, Objective determination of source parameters and similarity of earthquakes of different size, in: S. Das and C.H.
Scholz (Editors), Earthquake Source Mechanics, Am. Geophys. Union Monogr. 37, 259-268.

Atkinson, G.M., 1984, Attenuation of strong ground motion in Canada from a random vibrations approach, Bull. Seism. Soc. Am. 74, 2629-2653.

Atkinson, G.M., 1993, Source spectra for earthquakes in eastern North America, Bull. Seism. Soc. Am. 83, 1778-1798.

Atkinson, G.M. and Boore, D.M., 1995, Ground-motion relations for eastern North America, Bull. Seism. Soc. Am. 85, 17-30.

Bay, F., Fäh, D., Malagnini, L. and Giardini, D., 2003, Spectral shear wave ground motion scaling in Switzerland, Bull. Seism. Soc. Am. 93, 414-429.

Bender, B. and Perkins, D.M., 1987, SEISRISK III: A computer program for seismic hazard estimation. Open-File Report, U.S. Geological Survey.

Boatwright, J., 1984, Seismic estimates of stress release, J. Geophys. Res. 89, 6961-6968.

Boatwright, J. and Choy, G.L., 1992, Acceleration source spectra anticipated for large earthquakes in North America, Bull. Seism. Soc. Am. 82, 660-682.

Boore, D.M., 1983, Stochastic simulation of high-frequency ground motion based on seismological models of the radiated spectra, Bull. Seism. Soc. Am. 73, 1865-1894.

Boore D.M. and Joyner, W.B., 1997, Site amplifications for generic rock sites, Bull. Seism. Soc. Am. 87, 327-341.

Boore, D.M., 2001, Fortran programs for simulating ground motions from earthquakes: Version 2.0 - A revision of Open-File Report 96-80-A, Open-File Report 00-509, U.S. Geological Survey.

Boore, D.M., 2003, Prediction of ground motion using the stochastic method, Pure and Applied Geophys. 160, 635-676.

Braunmiller, J., Deichmann, N., Giardini, D. and Wiemer, S., 2005, Homogeneous moment magnitude calibration in Switzerland: Bull. Seismol. Soc. Am., in press.

Brune, J.N., 1970, Tectonic stress and the spectra of seismic shear waves from earthquakes, J. Geophys. Res. 75, 4997-5009.

Brune, J.N., 1971, Correction, J. Geophys. Res. 76, 5002.

Cartwright, D.E. and Longuet-Higgins, M.S., 1956, The statistical distribution of the maxima of a random function, Proc. Roy. Soc. London A237, 212-232.

Choy, G.L. and Boatwright, 1995, Global patterns of radiated seismic energy and apparent stress, J. Geophys. Res. 100, 1820518226.

Cocco, M. and Rovelli, A., 1989, Evidence for the variation of stress drop between normal and thrust faulting earthquakes in Italy, $J$. Geophys. Res. 94, 9399-9416.

Cornell, C.A., 1968, Engineering seismic risk analyses. Bull. Seism. Soc. Am. 58, 1583-1606.

Deichmann, N., 1992, Structural and rheological implications of lower-crustal earthquakes below northern Switzerland, Phys. Earth Plant. Int. 69, 270-280.

Deichmann, N., Baer, M., Braunmiller, J., Ballarin Dolfin, D., Bay, F., Delouis, B., Fäh, D., Giardini, D., Kastrup, U., Kind, F., Kradolfer, U., Künzle, W., Röthlisberger, S., Schler, T., Salichon, J., Sellami, S., Spühler, E. and Wiemer, S., 2000, Earthquakes in Switzerland and surrounding regions during 1999, Eclogae Geol. Helv. 93, 395-406.

EPRI, 1988, Engineering model of earthquake ground motion for eastern North America Electric power Research Institute, Palo Alto, California, EPRI NP-6074.

EPRI, 1993, Guidelines for site specific ground motions, Electric Power Research Institute, Palo Alto, California TR-102293. 
Fäh, D., Giardini, D., Bay, F., Bernardi, F., Braunmiller, J., Deichmann, N., Furrer, M., Gantner, L., Gisler, M., Isenegger, D., Jimenez, M.J., Kastli, P., Koglin, R., Masciadri, V., Rutz, M., Scheidegger, C., Schibler, R., Schorlemmer, D., SchwarzZanetti, G., Steimen, S., Sellami, S., Wiemer, S. and Wössner, J., 2003, Earthquake Catalogue of Switzerland (ECOS) and the related macroseismic database, Eclogae Geologicae Helvetiae 96, 219-236.

Field, E.H., and the SCEC Phase III Working Group, 2000, Accounting for site effects in probabilistic seismic hazard analyses of Southern California: Overview of the SCEC Phase III Report, Bull. Seism. Soc. Am. 90, 1-31.

Grünthal, G. (Ed.), 1998, European macroseismic scale 1998. Cahiers du Centre Européen de Géodynamique et de Séismologie 1998; Vol. 15, 100 pp.

Hanks, T. and McGuire, R.K., 1981, The character of high-frequency strong ground motion, Bull. Seism. Soc. Am. 71, 2071-2095.

Hough, S.E., 1996, Observational constraints on earthquake source scaling: Understanding the limits in resolution, Tectonophysics 261, 83-95.

Hsü, K.J., 1995, The Geology of Switzerland, Princeton University Press, cop., Princeton, New Jersey, USA.

Ide, S. and Beroza, G.C., 2001, Does apparent stress vary with earthquake size? Geophys. Res. Letts. 28, 3349-3352.

Ide, S., Beroza, G.C., Prejean, S.G. and Ellsworth, W.L., 2003, Apparent break in earthquake scaling due to path and site effects on deep borehole recordings, J. Geophys. Res. 108(B5): art. no. 2271.

Joyner, W.B. and Boore, D.M., 1981, Peak horizontal acceleration and velocity from strong motion records including records from the 1979 Imperial Valley, California, earthquake, Bull. Seism. Soc. Am. 71, 2011-2083.

Kanamori, H., Hauksson, E., Hutton, L.K. and Jones, L.M., 1993, Determination of earthquake energy release and ML, using TERRAscope, Bull. Seism. Soc. Am. 83, 330-346.

Kanamori, H.E. and Anderson, D.L., 1975, Theoretical basis of some empirical relations in seismology, Bull. Seism. Soc. Am. 65, 1073 1095.

Kastrup, U., Zoback, M.L., Deichmann, N., Evans, K., Michael, A.J. and Giardini, D., 2003, Stress field variations in the Swiss Alps and the northern Alpine Foreland derived from inversion of fault plane solutions, J. Geophys. Res., in press.

Kvamme, L.B., Hansen, R.A. and Bungum, H., 1995, Seismic-source and wave-propagation effects of $\mathrm{Lg}$ waves in Scandinavia, Geophys. J. Int. 120, 525-536.

Kind, F., Fäh, D. and Giardini, D., 2002, Application of an array technique to ambient vibrations, submitted to Geophysical J. Int.

Margaris, B.N. and Boore, D.M., 1998, Determination of $\Delta \sigma$ and $\kappa_{0}$ from response spectra of large earthquakes in Greece, Bull. Seism. Soc. Am. 88, 170-182.

Mai, P.M. and Beroza, G.C., 2000, Source scaling properties from finite-fault rupture models. Bull. Seism. Soc. Am. 90, 604-615.

Malagnini, L., Herrmann, R.B. and Di Bona, M., 2000a, Groundmotion scaling in the Apennines (Italy), Bull. Seism. Soc. Am. 90, 1062-1081.

Malagnini, L., Herrmann, R.B. and Koch, K., 2000b, Regional ground-motion scaling in central Europe, Bull. Seism. Soc. Am. 90, 1052-1061.

Malagnini, L. and Herrmann, R.B., 2000, Ground motion scaling in the region of the 1997 Umbria-Marche earthquakes (Italy), Bull. Seism. Soc. Am. 90, 1041-1051.
Mayeda, K. and Walter, W.R., 1996, Moment, energy, stress drop, and source spectra of western United States earthquakes from regional coda envelopes, J. Geophys. Res. 101, 11195-11208.

McGarr, A., 1999, On relating apparent stress to the stress causing earthquake fault slip, J. Geophys. Res. 104, 3003-3011.

McGuire, R.K. and Hanks, T.C., 1980, RMS acceleration and spectral amplitudes of strong ground motion during the San Fernando, California, earthquake, Bull. Seism. Soc. Am. 70, 1907-1919.

NEHRP, 1994, Recommended Provisions for the Development of Seismic Regulations for New Buildings, Part 1: Provisions Report No. FEMA 222, Federal Emergency Management Agency, Washington, D.C., U.S.A., 1995.

Nuttli O.W., 1983a, Empirical magnitude and spectral scaling relations for mid-plate and plate-margin earthquakes, Tectonophysics 93, 207-223.

Nuttli, O.W., 1983b, Average seismic source-parameter relations for mid-plate earthquakes, Bull. Seism. Soc. Am. 73, 519535.

Pavoni, N., Maurer, H., Roth, P. and Deichmann, N., 1997, Seismicity and seismotectonics of the Swiss Alps, Deep structures of the Swiss Alps, results of NRP 20, Birkhäuser, Basel, Switzerland, 241-250.

Perez-Campos, X. and Beroza, G.C., 2001, An apparent mechanism dependence of radiated seismic energy, J. Geophys. Res. 106, 11127-11136.

Raoof, M., Herrmann, R.B. and Malagnini, L., 1999, Attenuation and excitation of three-component ground motion in Southern California, Bull. Seism. Soc. Am. 89, 888-902.

Sabetta, F., and Pugliese, A., 1987, Attenuation of peak horizontal acceleration and velocity from Italian strong-motion records, Bull. Seism. Soc. Am. 77, 1491-1513.

Silva, W. and Darragh, R., 1995, Engineering characterization of earthquake strong ground motions recorded at rock sites. Electric Power Research Inst. Report TR-102261, Palo Alto, California.

Singh, S.K. and Ordaz, M., 1994, Seismic energy release in Mexican subduction zone earthquakes, Bull. Seism. Soc. Am. 84, 15331550.

Smit, P., 1996, Datenerfassung und Bestimmung der Abminderung der Bodenbewegung bei Erdbeben in der Schweiz, PhD. Thesis, ETH-Zurich.

Toro, G.R. and McGuire, R.K., 1987, An investigation into earthquake ground motion characteristics in eastern North America, Bull. Seism. Soc. Am. 77, 464-489.

Toro, G.R., Abrahamson, N.A. and Schneider, J.F., 1997, Model of strong ground motions from earthquakes in central and eastern North America: Best estimates and uncertainties, Seism. Res. Letts. 6, 41-57.

Trümpy, R., 1985, Die Plattentektonik und Entstehung der Alpen, Orell Füssli, Zurich, Switzerland.

Wills, C.J., Petersen, M., Bryant, W.A., Reichle, M., Saucedo, G.J., Tan, S., Taylor, G. and Treiman, J., 2000, A site-condition map for California based on geology and shear-wave velocity, Bull. Seism. Soc. Am. 90, 187-208.

Wiemer, S., Giardini, D., Fäh, D., Deichmann, N., Sellami, S. and Jenny, S., 2005, New probabilistic seismic hazard assessment for Switzerland, Bull. Seism. Soc. Am. submitted.

Wössner, J., Treml, M. and Wenzel, F., 2002, Synthetic ground motions $M_{\mathrm{w}}=6.0$ earthquakes in the Upper Rhinegraben using Empirical Green's Functions, submitted to Geophys. J. Int.

Yazd, M.R.S., 1993. Ground motion studies in the southern Great Basin of Nevada and California, PhD. Thesis, St. Louis University. 